\title{
Maximum thermal conductance for a micro-channel, utilising Newtonian and non-Newtonian fluid
}

\author{
M.D. Stocks, T. Bello-Ochende ${ }^{\mathrm{a}}$, J.P. Meyer \\ Department of Mechanical and Aeronautical Engineering, University of Pretoria, Pretoria, Private Bag X20, \\ Hatfield, 0028, South Africa. \\ ${ }^{a}$ Email: tunde.bello-ochende@uct.ac.za, Tel: +27 21 650-3673, Fax: +27 21 650-3240
}

\begin{abstract}
This paper investigates the thermal behaviour of two micro-channel elements cooled by Newtonian and non-Newtonian fluids, with the objective to maximise thermal conductance subject to constraints. This is done firstly for a two-dimensional duct micro-channel and secondly for a three-dimensional complex micro-channel. A numerical model is used to solve the governing equations relating to flow and temperature fields for both cases. The geometric configuration of each cooling channel is optimised for Newtonian and nonNewtonian fluid at a fixed inlet velocity and heat flux. In addition, the effect of porosity on thermal conductance is investigated. It was found, in both cases, that the non-Newtonian fluid characteristics result in a significant variation in thermal conductance as inlet velocity is increased. The characteristics of a dilatant fluid greatly reduce thermal conductance on account of shear thickening on the boundary surface. In contrast, a pseudoplastic fluid shows increased thermal conductance. A comparison of the complex micro-channel and the duct micro-channel shows the improved thermal conductance resulting from greater flow access to the conductive area, achieved by the complex micro-channel.
\end{abstract}

Keywords: Non-Newtonian fluid; Thermal conductance; Geometric optimisation; Microchannel; Complex geometry 


\section{Nomenclature}

Latin symbols

A total channel area, $\mathrm{m}^{2}$

C global thermal conductance

$C_{p} \quad$ specific heat, $\mathrm{J} / \mathrm{K}$

d channel depth, $\mathrm{m}$

$D_{1} \quad$ diameter of channel before branching, $\mathrm{m}$

$D_{2} \quad$ diameter of channel after branching, m

$H \quad$ total channel height, $\mathrm{m}$

$k \quad$ thermal conductivity, $\mathrm{W} / \mathrm{mK}$

K consistency, Pa.s ${ }^{0.5}$

$L \quad$ total channel length, $\mathrm{m}$

$L_{1} \quad$ length of channel before branching, $\mathrm{m}$

$L_{2} \quad$ length of channel after branching, $\mathrm{m}$

n power law index

$P \quad$ pressure, $\mathrm{Pa}$

$q \quad$ total heat transfer, W

$R \quad$ global thermal resistance

Re Reynolds number

$T \quad$ temperature, $\mathrm{K}$

$U \quad$ average velocity, $\mathrm{m} / \mathrm{s}$

$\vec{U} \quad$ velocity vector, $\mathrm{m} / \mathrm{s}$

$V \quad$ total channel volume, $\mathrm{m}^{3}$ 


\section{Greek symbols}

$\alpha \quad$ ratio of $L_{1}$ to $L$

$\dot{\gamma} \quad$ rate of strain

$\theta \quad$ angle between branches, radians

$\mu \quad$ viscosity, $\mathrm{kg} / \mathrm{m} \cdot \mathrm{s}$

$\rho \quad$ density, $\mathrm{kg} / \mathrm{m}^{3}$

$\varphi \quad$ porosity ratio

\section{Superscripts}

$\sim \quad$ Dimensionless variable

Subscripts

$\max$ maximum

in inlet

\section{INTRODUCTION}

Advances in the field of electronic manufacturing and design have resulted in a drive to increase the density of electronic systems, resulting in higher heat generation density [1]. This has led to a requirement for novel methods of extracting more heat from smaller systems and increasing the efficiency of existing heat extraction systems.

For more than a decade this drive has resulted in a significant amount of research being done in the field of micro-channels and micro-channel materials [2-5] in order to maximise the heat transfer density rate. More recently, researchers have become interested in the use of nanofluids as working fluids in micro-channel cooling, a technique that has yielded successful results [6-8].

Research has been conducted regarding the flow of non-Newtonian fluids in a heat transfer environment, within micro-channels [9][10]. Das and Chakraborty [11] derived analytical 
solutions that are used to describe the transport characteristics of non-Newtonian fluids under electroosmotically driven flow. The authors further investigated the effect of non-Newtonian fluids, specifically of blood, on velocity, temperature and concentration distribution within a micro-channel, under electroosmotically driven flow conditions. The authors found a relatively insignificant impact on the temperature distribution of the non-Newtonian fluid.

Bello-Ochende et al. [12] conducted the geometric optimisation of a micro-channel heat sink with the objective to find an optimal geometry to minimise the peak temperature. This was done using constructal theory principles, by means of which a structure is generated to maximise global performance subject to global constraints. Such a structure is free to morph into an optimal configuration [13-15]. Bello-Ochende et al. found it was possible to obtain an optimal geometric aspect ratio for such a micro-channel for a fixed pressure drop, thereby maximising thermal conductance. With the use of mathematical optimisation algorithms, Bello-Ochende et al. [16] also found that a unique optimal geometric configuration exists for a given pressure drop across a channel, which will result in a minimum peak wall temperature.

Constructal theory promotes a paradigm shift away from conventional flow structures toward structures that offer greater flow access [17]. These flow structures are commonly found in nature, such as branching tree structures found in river deltas or the human lungs. In these complex flow structures, the fluid channel bifurcates, offering the working fluid greater access to the conductive area. It was found that an optimal ratio exists between the length and diameter of the branches for minimising flow resistance [13-15], [17].

This paper builds upon the work done by Bello-Ochende et al. [12], [16] whereby geometric optimisation of a micro-channel is conducted, however with the use of a non-Newtonian working fluid in both a simple and complex flow structure micro-channel. The objective is to maximise thermal conductance despite being constrained by a fixed total volume, inlet conditions and heat transfer rate. This paper aims to investigate an optimal geometric aspect ratio of the complex micro-channel and the effects of non-Newtonian fluid characteristics with the goal to maximise efficiency by increasing the thermal conductance. 


\section{TWO-DIMENSIONAL SIMPLE MICRO-CHANNEL}

\subsection{Model}

Consider a section of micro-channel with a total area $(A)$ fixed at $1 \times 10^{-4} \mathrm{~m}^{2}$ as shown in Fig. 1. The height $(H)$ and length $(L)$ are design parameters and are free to morph, subject to the global constraint of area. The ratio between the area of the solid and fluid is constrained by the porosity ratio $(\varphi)$. A uniform heat transfer rate $(q)$ is applied to the solid from the top and bottom and heat is extracted by the working fluid. Flow is assumed to be steady, laminar, incompressible and two-dimensional, with negligible heat transfer due to radiation and natural convection. Buoyancy forces are considered negligible.

The conservation of mass, momentum and energy equations are respectively:

$$
\begin{gathered}
\nabla(\rho \vec{U})=0 \\
\rho(\vec{U} \cdot \nabla \vec{U})=-\nabla P+\mu \nabla^{2} \vec{U} \\
\rho C_{p}(\vec{U} \cdot \nabla T)=k_{f} \nabla^{2} T
\end{gathered}
$$

where $\nabla^{2}=\partial^{2} / \partial x^{2}+\partial^{2} / \partial y^{2}+\partial^{2} / \partial z^{2}$ and the Cartesian coordinates $(x, y)$ and velocity component $(u, v)$ are defined in Fig. 1. The variables are defined in the nomenclature. For a volume occupied by a solid, the momentum (2) and energy (3) equations reduce to:

$$
\begin{gathered}
\vec{U}=0 \\
k_{s} \nabla^{2} T=0
\end{gathered}
$$

The inlet boundary condition is set to:

$$
\begin{aligned}
\vec{U} & =u_{i n} \\
T & =T_{i n}
\end{aligned}
$$

and no slip occurs on the wall of the channel and pressure outlet. The thermal boundary condition consists of uniform heat flux, calculated to ensure a constant total heat transfer rate $(1 \mathrm{~W})$ that is applied to the top and bottom of the solid:

$$
k_{s} L \frac{\partial T}{\partial y}=-q^{\prime}
$$

The remaining boundaries are modelled as symmetry planes with free slip, so as to represent an infinite channel, thus: 


$$
\begin{aligned}
& \frac{\partial \vec{U}}{\partial(x, y)}=0 \\
& \frac{\partial T}{\partial(x, y)}=0
\end{aligned}
$$

As mentioned above, the porosity ratio $(\varphi)$ is a measure of the ratio between the solid and fluid:

$$
\varphi=\frac{A_{s}}{A}
$$

where the total area of the solid can be expressed as follows:

$$
A_{s}=(H-D) L
$$

Substituting equation (11) into (10), the porosity ratio can be manipulated to:

$$
\varphi=1-\frac{D}{H}
$$

Thus from equation (12) the duct diameter can be determined:

$$
D=H(1-\varphi)
$$

For this model, the solid was tested using three different materials, each with known thermal coefficients, namely silicon, aluminium and copper.

In order to model the non-Newtonian fluid, the Ostwald de Waele or power law model [9], [10], [18] is used, according to which viscosity is a function of consistency $(K)$ and the power law index $(n)$ :

$$
\mu(\dot{\gamma})=K \dot{\gamma}^{n-1}
$$

A consistency $(K)$ value of 20 Pa.s ${ }^{0.5}$ was used in conjunction with three index $(n)$ values:

- $n=0.5 \quad$ Pseudoplastic (Shear thinning)

- $n=1.0 \quad$ Newtonian

- $n=1.5 \quad$ Dilatant (Shear thickening)

The objective is to minimise the difference between the maximum and minimum temperatures across the micro-channel (both fluid and solid) at various inlet velocities and porosity values by utilising Newtonian and non-Newtonian fluids. Thus the geometric configuration that maximises heat transfer and thermal conductance is found. Thermal conductance (heat transfer per unit time) in dimensionless form is defined as follows [12]: 


$$
C=\frac{q^{\prime \prime} L}{k\left(T_{\max }-T_{\text {in }}\right)}
$$

Here $q^{\prime \prime}$ is defined as the heat flux and $k$ as the thermal conductivity of the fluid. Manipulating equation (15) yields the following for a constant heat flux $(q)$ across the characteristic length $A^{1 / 2}$ :

$$
C=\frac{q}{A^{1 / 2} k \Delta T}
$$

where the thermal conductance is a function of $\Delta T$ alone.

Thermal conductance $(C)$ is a dimensionless form of expressing the ratio of the heat transfer rate to the largest excess temperature, which is expected to occur in the exit plane of the micro-channel. The dimensionless thermal resistance, $R$, is given by the reciprocal of thermal conductance:

$$
R=\frac{1}{C}
$$

\subsection{Numerical Method}

The governing equations (1) to (3) are discretised and solved using the finite volume method with polyhedral elements [19]. The Segregated Flow and Segregated Fluid Temperature models are used to simulate the fluid flow and energy in conjunction with a second-order upwind scheme to model the convection-diffusion effect in the transport equations. Secondary gradients are employed for both the interior and boundaries. The formulation makes use of a collocated variable arrangement and a Rhie-and-Chow-type pressure-velocity coupling combined with a SIMPLE algorithm to solve the system of equations [19].

Convergence is met once the residuals, including that of energy, as well as the temperature monitor have reached an acceptable accuracy of $10^{-4}$.

A mesh refinement study was conducted to obtain mesh independent numerical solutions. An asymmetric mesh was constructed with double refinement in the $x$ direction and extensive refinement at the fluid boundary layer in order to accurately capture the non-Newtonian characteristics. A summary of the mesh refinement study for a characteristic geometric configuration is captured in Table 1. A generic mesh was tested on a characteristic geometry. 
By adequately refining and optimising the mesh for this geometry, it is possible to obtain a suitable mesh that can be adapted for all the geometric configurations. It was found that refining the mesh above 30912 cells yields a change in the thermal resistance of less than 1\%. Thus 30912 cells were deemed sufficient to achieve mesh independence for all results.

\subsection{Numerical Results}

The flow was simulated at various different inlet velocity ranges for porosity ratios of 0.95 , 0.9 and 0.8. Three materials with known thermal conductivity were used as the solid material, namely silicon $(k=124 \mathrm{~W} / \mathrm{mK})$, aluminium $(k=237 \mathrm{~W} / \mathrm{mK})$ and copper $(k=398$ $\mathrm{W} / \mathrm{mK}$ ). A constant heat transfer rate of $1 \mathrm{~W}$ was applied to the top and bottom boundary of the solid. This was done for three power law exponents in order to obtain a comparison between Newtonian and non-Newtonian fluid. For each fluid-solid configuration, geometric optimisation was done so as to obtain a maximum global thermal conductance. Thus an optimal duct was found, as illustrated in Fig. 2. As $R e$ is a function of viscosity and affected by non-Newtonian fluids, the thermal conductance of the various configurations and fluids are compared according to inlet velocity, which is fixed.

Fig. 3 indicates the process of geometric optimisation, whereby an optimal geometric ratio $H / L$ is obtained once the excess temperature $\Delta T$ is minimised $\left(\Delta T_{\min }\right)$. The optimal ratio $H / L$, for a silicon micro-channel with porosity of 0.95 and $0.05 \mathrm{~m} / \mathrm{s}$ inlet velocity, in Fig. 3 is shown to vary only slightly at $0.7,0.7$ and 0.6 for a pseudoplastic, Newtonian and the dilatant fluid respectively. However the non-Newtonian characteristics can be seen to have a larger effect on the excess temperature at these optimum values.

The optimal geometric ratio $H / L$ is found to be dependent on the inlet velocity.

Fig. 4 indicates this relation, for an inlet velocity range of $0.014 \mathrm{~m} / \mathrm{s}\left(R e_{N e w} \sim 150\right)$ to 0.062 $\mathrm{m} / \mathrm{s}\left(\boldsymbol{R} \boldsymbol{e}_{\mathrm{New}} \sim 700\right)$. As the inlet velocity, and therefore $R e$, is increased, the thermal boundary layer thickness is reduced and only converges further downstream. Thus the optimal configuration is lengthened. Consequently it can be stated that as $v_{i n} \sim \infty$, thus $H / L \sim 0$. A further increase of $L$ beyond the optimum will result in an overworked fluid, and $\Delta T_{\min }$ will systematically rise again as seen in Fig. 3. In addition, 
Fig. 4 indicates the $H / L$ ratio is less sensitive to inlet velocity increase as the porosity is decreased (i.e. the percentage of fluid in relation to solid is increased). At a porosity of 0.8 , the $H / L$ ratio remains fairly constant throughout the inlet velocity range.

As the inlet velocity is increased, the optimal $\Delta \mathrm{T}_{\min }$ obtained is seen to decrease. Fig. 5 indicates the asymptotic nature of the excess temperature change to inlet velocity. It can be concluded from this figure that a further increase in inlet velocity will have a decreasing effect on the excess temperature. As a higher inlet velocity increases the pressure drop and required pumping power, it will merely reduce overall system efficiency.

The thermal conductance, derived above for silicon in the range of $0.014 \mathrm{~m} / \mathrm{s} \leq v_{\text {in }} \leq$ $0.062 \mathrm{~m} / \mathrm{s}$ and $0.5 \leq n \leq 1.5$, is summarised in Fig. 6. As the velocity increases, the thermal conductance increases approximately linearly for a Newtonian fluid. However, at higher inlet velocities the effect of the non-Newtonian characteristics becomes more pronounced. It was found at higher inlet velocities that the dilatant (shear thickening, $n=$ 1.5) characteristics result in a reduced thermal conductance. This may be attributed to the action of shear thickening, where shear force is increased at the wall, which in turn leads to a thickening of the dilatant fluid. As a result, the heat transfer coefficient at the wall is reduced and heat transfer is significantly impaired, resulting in a decrease in thermal conductance of $13 \%$ from the benchmark Newtonian fluid. The opposite effect is found with a pseudoplastic fluid, whereby a shear thinning action is experienced at the wall, further increasing the heat transfer coefficient and resulting in an increase in the thermal conductance. Fig. 6 captures this divergence from the Newtonian fluid. This phenomenon will be accentuated as the viscosity (higher consistency $K$ ) of the fluid is increased.

Fig. 7 illustrates the effect of the solid material thermal conductivity $(k)$ increase from 124 $\mathrm{W} / \mathrm{mK}$ of $\mathrm{Si}$ to $398 \mathrm{~W} / \mathrm{mK}$ of $\mathrm{Cu}$. This accounts for only an approximate $3 \%$ increase in global thermal conductance, indicating the insensitivity towards the solid material used. However, a decrease in porosity leads to a higher mass flow rate and in turn results in a higher thermal conductance, as can be seen in Fig. 7.

Granting that the increased thermal conductance for a pseudoplastic fluid over a Newtonian fluid is relatively small at low inlet velocities (or $R e_{N e w}$ ), the fluid holds the advantage of becoming less viscous as shear force is increased, typically at locations such as a wall or where high flow resistance is encountered. Thus the pseudoplastic nature of the fluid will result in a reduced viscosity, which in turn will result in lower flow resistance. As a 
consequence, the total pressure drop across a system can be significantly reduced, thereby increasing system efficiency. Fig. 8 indicates the substantial increase in normalised pressure drop across the micro-channel for a dilatant fluid $(n=1.5)$ compared to a Newtonian fluid, and conversely the reduced pressure drop incurred by a pseudoplastic $(n=0.5)$ fluid. The pseudoplastic non-Newtonian characteristic results in a significantly lower pressure drop across the micro-channel.

\section{THREE-DIMENSIONAL COMPLEX MICRO-CHANNEL}

\subsection{Model}

Now consider a complex micro-channel element of Fig. 10, as shown in Fig. 9, with a total volume $(V)$ fixed at $2 \times 10^{-7} \mathrm{~m}^{3}$. The depth is fixed at $0.002 \mathrm{~m}$, yielding a total micro-channel cross-sectional area of $1 \times 10^{-4} \mathrm{~m}^{2}$. The position at which the fluid channel branches is fixed at the optimum position so as to minimise flow resistance, which has been found to be

$L_{1}=2^{1 / 3} L_{2}$ with the duct diameters being $D_{1}=2^{1 / 3} D_{2}$ [17], [20], [21] for laminar flow. The height $(H)$ and length $(L)$ are design parameters and are free to morph, subject to the global constraints of the cross-sectional area. The ratio between the fluid and solid material is constrained by the porosity ratio $(\varphi)$. A uniform heat transfer rate $(q)$ is applied to the solid from the top and bottom and heat is extracted by the fluid. Flow is assumed to be laminar, incompressible and steady, with negligible heat transfer due to radiation and natural convection. Buoyancy forces are considered negligible.

The equations for conservation of mass, momentum and energy, as well as the boundary conditions remain the same as for the two-dimensional duct micro-channel.

Symmetry planes were used on both $x y$ planes, where

$$
\begin{gathered}
\frac{\partial \vec{U}}{\partial(x, y)}=0 \\
\frac{\partial T}{\partial(x, y)}=0
\end{gathered}
$$

Again the porosity ratio $(\varphi)$ is a measure of the ratio between the solid and fluid, given by:

$$
\begin{gathered}
\varphi=\frac{V_{s}}{V} \\
\therefore \varphi=\frac{d A_{s}}{d A}=\frac{A_{s}}{A}
\end{gathered}
$$


Taking into account the optimal diameter and length ratio given above:

$$
\begin{aligned}
& D_{1}=2^{1 / 3} D_{2} \\
& L_{1}=2^{1 / 3} L_{2}
\end{aligned}
$$

the length $L_{1}$ can be written as:

$$
\begin{gathered}
\left(1+\frac{\cos \theta}{2^{1 / 3}}\right) L_{1}=L \\
\alpha L_{1}=L \\
\therefore \alpha=\left(1+\frac{\cos \theta}{2^{1 / 3}}\right)
\end{gathered}
$$

and

$$
A_{s}=H L-D_{2}\left(2^{1 / 3} L_{1}+2 L_{2}\right)
$$

Thus equation (21) can be manipulated to:

$$
\varphi=1-\frac{D_{2}}{H}\left(2^{1 / 3} \alpha+\frac{2(1-\alpha)}{\cos (\theta)}\right)
$$

As the porosity value is fixed, it can be used to determine the diameter of the duct branches. Therefore equation (28) can be re-written as follows:

$$
D_{2}=\frac{(1-\varphi) H}{\left(2^{1 / 3} \alpha+\frac{2(1-\alpha)}{\cos \theta}\right)}
$$

Thermal conductance (heat transfer per unit time) in dimensionless form for the threedimensional complex micro-channel with characteristic length $V^{1 / 3}$ is given by:

$$
C=\frac{q}{V^{1 / 3} k \Delta T}
$$

The non-Newtonian fluid model remains unchanged for the complex micro-channel numerical simulation.

\subsection{Numerical Method}

As in the simple micro-channel, the governing equations (1) to (3) are discretised and solved using the finite volume method with polyhedral elements [19]. The Segregated Flow and Segregated Fluid Temperature models are used to simulate the fluid flow and energy in conjunction with a second-order upwind scheme to model the convection-diffusion effect in 
the transport equations. Secondary gradients are employed for both the interior and boundaries. The formulation makes use of a collocated variable arrangement and a Rhie-andChow-type pressure-velocity coupling combined with a SIMPLE algorithm to solve the system of equations [19].

Convergence is met once the residuals (including that of energy) and the temperature monitor have reached an acceptable accuracy of $10^{-4}$.

A mesh refinement study was conducted to obtain mesh independence. A structured mesh was used with extensive refinement in the fluid boundary layer in order to accurately capture the non-Newtonian characteristics. As mentioned, a symmetry boundary condition was modelled in the $x y$ plane to halve the computational domain, therefore reducing CPU time. Table 2 gives a summary of the mesh refinement study for a characteristic geometry. By adequately refining the mesh for this characteristic geometry, it was possible to obtain a highquality generic mesh that can be modified for all the geometric configurations. It was found that the results converged for a mesh of more than 146245 cells, accounting for merely a $0.08 \%$ change if the number of cells was doubled. Thus a mesh of 146245 cells was deemed sufficient to obtain mesh independence for all geometries.

\subsection{Numerical Results}

The three-dimensional flow through a complex micro-channel was simulated at various inlet velocity ranges for porosity ratios of $0.95,0.9$ and 0.85 . The material used for the microchannel was silicon with known thermal conductivity $(k=124 \mathrm{~W} / \mathrm{mK})$. A constant heat transfer rate $(1 \mathrm{~W})$ was applied to the top and bottom boundary of the solid. This was done for the same three fluids, as in the simple case, with different power law exponents $(n=0.5$; $n=1 ; n=1.5)$ to draw a comparison between Newtonian $(n=1)$ and non-Newtonian fluid. Geometric optimisation was done for each fluid-solid configuration to obtain a maximum global thermal conductance. Thus an optimal duct, such as in Fig. 11, was obtained.

Fig. 12 indicates the process of geometric optimisation whereby an optimal geometric ratio $H / L$ for the complex micro-channel is obtained, for a porosity of 0.9 and an inlet velocity of $0.07 \mathrm{~m} / \mathrm{s}$. From the figure it can be seen that the optimal geometric ratio $H / L$ is 0.5 for both the pseudoplastic $(n=0.5)$ and Newtonian $(n=1)$ fluid, whereas it is 0.6 for a dilatant fluid $(n=1.5)$. This is only a slight variation. However, the non-Newtonian characteristic of the dilatant fluid can be seen to have a significant effect on the excess temperature. 
As in the case of the two-dimensional simple micro-channel, the optimal geometric ratio proves to be highly dependent on the inlet velocity. Fig. 13 indicates this relation for an inlet velocity range from $0.03 \mathrm{~m} / \mathrm{s}\left(R e_{\text {new }} \sim 340\right)$ to $0.1 \mathrm{~m} / \mathrm{s}\left(R e_{\text {new }} \sim 1100\right)$. Again it can be seen that the optimal geometry is lengthened with the increase in inlet velocity $\left(v_{\text {in }} \sim \infty\right.$, thus $H / L \sim 0)$. As the heat transfer is convectively driven, a decrease of $L$ below the optimum will allow an underworked fluid to escape the heat transfer domain, resulting in an increased excess temperature $\left(\Delta T_{\min }\right)$ in the conductive space. Similarly, a further increase of $L$ beyond the optimum will result in an overworked fluid, and $\Delta T_{\min }$ will systematically rise again, as seen in Fig. 12.

It is clear from Fig. 13 that the $H / L$ ratio is less sensitive to variation in inlet velocity as the porosity is decreased (i.e. the percentage of fluid in relation to solid is increased). Thus, at a porosity of 0.85 , the $H / L$ ratio remains fairly constant throughout the inlet velocity range.

It was found that as the inlet velocity increases, the optimal $\Delta T_{\min }$ obtained decreases, however in Fig. 14 this relation can be seen to have an asymptotic nature. Thus it can be concluded that an additional increase in inlet velocity will have a reduced effect upon $\Delta T_{\text {min }}$. As a higher inlet velocity increases the pressure drop and required pumping power, it will merely reduce overall system efficiency.

The thermal conductance derived above for the range of $0.03 \mathrm{~m} / \mathrm{s} \leq v_{\text {in }} \leq 0.1 \mathrm{~m} / \mathrm{s}$ and 0.5 $\leq n \leq 1.5$ is summarised in Fig. 15 and Fig. 16. At lower inlet velocities, the thermal conductance increases approximately linearly. However, at higher inlet velocities the effect of the non-Newtonian characteristics becomes more pronounced. It can be seen from Fig. 15 that the dilatant fluid $(n=1.5)$ characteristic results in a reduced thermal conductivity. This may be attributed to the action of shear thickening, where at the wall the shear force is increased, which in turn leads to a thickening of the dilatant fluid. The branch of the complex structure leads to a further increase in shear force, decreasing the thermal conductance of the fluid. As a result, the heat transfer coefficient at the wall is reduced and heat transfer is significantly impaired, causing a decrease in thermal conductance of $23 \%$ from the benchmark Newtonian fluid.

In contrast, the shear thinning action experienced at the wall for a pseudoplastic fluid leads to an increased fluid velocity at the thermal boundary, therefore increasing the convective heat 
transfer coefficient at the fluid-solid interface. Fig. 15shows that this results in an increased thermal conductance.

Fig. 16 indicates the effect of porosity on the thermal conductance. Reducing the porosity leads to a higher mass flow rate, which in turn leads to a higher thermal conductance. It can be noted that the divergence pattern between the fluids is similar for all porosities, however slightly more pronounced at the lower value of 0.85 .

Fig. 17 illustrates the significant increase in normalised pressure drop across the complex micro-channel for a dilatant fluid $(n=1.5)$ compared to a Newtonian fluid and, conversely, the dramatic reduction in normalised pressure drop $(\sim 70 \%)$ for a pseudoplastic fluid $(n=$ $0.5)$. Thus the total pressure drop across a system can be significantly reduced with the use of a pseudoplastic fluid. Coupled with the increase in thermal conductance achieved by a pseudoplastic fluid, albeit small, such reduced pressure drop may bring about significantly increased system efficiency.

\section{SCALE ANALYSIS}

The numerical results obtained were compared to that of Bello-Ochende et al.[12], where results were based on a three-dimensional micro-channel heat sink with heat flux from below. By manipulating the Reynolds number to be a function of the Bejan number [16], [17], BelloOchende et al.[12] used theoretical analysis to predict that the maximum thermal conductance is given by:

$$
C_{\text {max, }} \text { theory }=0.6 B e^{0.49}
$$

Data obtained through numerical analysis of the three-dimensional complex micro-channel (with heat flux from both the top and bottom) indicates a maximum thermal conductance as a function of the Reynolds number, namely:

$$
C_{\text {max }}=0.13\left(\frac{B e}{P r}\right)^{0.3} \approx B e^{0.3}
$$

Thus the data obtained shows similar trends as found by Bello-Ochende et al.[12] and [16]. Bello-Ochende et al. also[12] validated their results by comparing them to data of $\mathrm{Qu}$ and Mudawar [22]. 


\section{COMPARISON OF SIMPLE AND COMPLEX MICRO-CHANNEL}

An identical process of geometric optimisation was followed for both the micro-channel models. It is observed from the results obtained that a similar trend persists in both cases, whereby an optimal geometric ratio exists for each inlet velocity. At this ratio, the excess temperature is minimised and thermal conductance is maximised. It was, however, found that the complex micro-channel produced a higher thermal conductivity at similar conditions. Fig. 18 summarises this enhanced thermal conductance obtained from the complex microchannel, as opposed to a simple micro-channel. In addition, when comparing Fig. 2 to Fig. 11, the highest temperature for the simple is found at the exit plane, in other words at the furthest point from the fluid. In Fig. 11 - the complex micro-channel - the fluid is directed to this specific point, which assists in reducing the specific hot spot temperature and increasing the thermal conductance of the micro-channel. Thus, the complex structure allows access to a greater area of the conductive space, resulting in a lower excess temperature and maximising thermal conductance.

Fig. 19 indicates that the normalised pressure drop for the complex micro-channel is only marginally larger than that of the simple micro-channel. This is achieved by utilising the optimal duct length and diameter ratio for the complex micro-channel. Moreover, at a higher inlet velocity, the optimal geometric ratio for a simple micro-channel is small (low $H / L$ ratio). This results in a very elongated geometry whereby the channel diameter is reduced and the flow resistance is increased. A comparison between

Fig. 4 and Fig. 13 shows that the geometric ratio for a simple micro-channel is significantly lower than that of the complex micro-channel. Consequently, it can be extrapolated that at higher inlet velocities the pressure drop across a simple micro-channel may surpass that of a complex micro-channel.

\section{CONCLUSION}

In this paper geometric optimisation was employed to maximise the thermal conductance for various flow configurations and to investigate the effect of a non-Newtonian working fluid on the heat transfer ability of a simple and complex micro-channel. It was found that an optimum geometry exists for each velocity inlet and porosity value, whereby the thermal 
conductance is maximised. Furthermore, the thermal conductance can be enhanced by increasing the velocity or decreasing the porosity value (i.e. higher ratio of fluid to solid). A dilatant (shear thickening) non-Newtonian fluid $(n=1.5)$ proves to greatly reduce the thermal conductivity.

The pseudoplastic non-Newtonian (shear thinning; $n=0.5$ ) effect on the thermal conductance is in both models only marginally increased over that of the Newtonian fluid $(n=1)$. However, as this effect is achieved in areas of higher shear stress, such as at the wall, the fluid becomes less viscous and hence the pressure drop over the channel will reduce. This should reduce the pumping requirements of such a fluid and, in addition to the marginal increase in thermal conductance, may significantly increase the efficiency of the system.

In conclusion - the analysis shows that a complex micro-channel affords the working fluid greater access to the conductive space and therefore increases the thermal conductance of the micro-channel to a substantial extent.

\section{ACKNOWLEDGEMENTS}

The authors acknowledge with gratitude the funding obtained from the NRF, TESP, University of Stellenbosch/University of Pretoria, SANERI/SANEDI, CSIR EEDSM Hub and NAC and the National Research Foundation (NRF-DST), as well as support from Aerotherm.

\section{REFERENCES}

[1] I. Mudawar (2001) Assessment of high-heat-flux thermal management Schemes. IEEE Transaction on Component and Packaging Technologies 24:122-141.

[2] M. M. Rahman (2000) Measurement of heat transfer in microchannel heat sinks. Int. Comm. Heat Mass Transfer 27:495-506

[3] K. C. Toh, X. Y. Chen, and J. C. Chai (2002) Numerical computation of fluid flow and heat transfer in microchannels. International Journal of Heat and Mass Transfer 45:5133-5141 
[4] J. Li and G. P. Peterson (2007) 3-Dimensional numerical optimization of silicon-based high performance parallel microchannel heat sink with liquid flow. International Journal of Heat and Mass Transfer 50:2895-2904

[5] A. G. Fedorov and R. Viskanta (2000) Three-dimensional conjugate heat transfer in the microchannel heat sink for electronic packaging. International Journal of Heat and Mass Transfer 43: 399-415

[6] J. Jung, H. Oh, and H. Kwak (2009) Forced convective heat transfer of nanofluids in microchannels. International Journal of Heat and Mass Transfer 52:466-472

[7] R. Chein and G. Huang (2005) Analysis of microchannel heat sink performance using nanofluids. Applied Thermal Engineering 25:3104-3114

[8] D. Wen and Y. Ding (2004) Experimental investigation into convective heat transfer of nanofluids at the entrance region under laminar flow conditions. International Journal of Heat and Mass Transfer 47:5181-5188

[9] M. Barkhordari and S. G. Etemad (2007) Numerical study of slip flow heat transfer of non-Newtonian fluids in circular microchannels. International Journal of Heat and Mass Transfer 28:1027-1033

[10] H. W. Kim, D. R. Jeng, and K. J. DeWitt (1983) Momentum and heat transfer in power-law fluid flow over two dimensional or axisymmetrical bodies. Journal of Heat Transfer 26(2):245-259

[11] S. Das and S. Chakraborty (2006) Analytical solutions for velocity, temperature and concentration distribution in electroosmotic microchannel flows of a non-Newtonian bio-fluid. Analytica Chimica Acta 559:15-24

[12] T. Bello-Ochende, L. Liebenberg, and J. P. Meyer (2007) Constructal cooling channels for micro-channel heat sinks. International Journal of Heat and Mass Transfer 50:4141-4150

[13] A. Bejan (2006) Constructal theory of pattern formation. Hydrology and Earth System Sciences Discussions 3(4):1773-1807

[14] A. Bejan (2006) Constructal theory of design in engineering and nature. Thermal Science 10(1):9-18

[15] A. Bejan and S. Lorente (2006) Constructal theory of generation of configuration in nature and engineering. Journal of Applied Physics 100(4) doi: 10.1063/1.2221896

[16] T. Bello-Ochende, J. P. Meyer, and F. U. Ighalo (2010) Combined Numerical Optimization and Constructal Theory for the Design of Microchannel Heat Sinks Numerical Heat Transfer, Part A : Applications - An International Journal of Computation and Methodology 58(11):882-889

[17] A. Bejan and S. Lorente (2008) Design with Constructal Theory. Whiley, USA 
[18] N. J. Balmforth and R. V Craster (2001) Geophysical Aspects of Non-Newtonian Fluid Mechanics, University of California 34-51

[19] CD-Adapco (2011) StarCCM+ User guide 6.02.007

[20] W. R. Hess (1914) Das Prinzip des kleinsten Kraftverbrauches im Dienste hämodynamischer Forschung. Archiv für Anatomie und Physiologie 1914:1-62

[21] C. D. Murray (1926) The physiological principle of minimum work. The vascular system and the cost of blood volume. Proc. N. A. S. I(12):207-214

[22] W. Qu and I. Mudawar (2002) Analysis of three-dimensional heat transfer in microchannel heat sinks 45:3973-3985 


\section{Figure Captions}

Figure 1: Two-dimensional simple micro-channel configuration

Figure 2: Temperature distribution and boundary layer formation (simple)

Figure 3: Optimal geometric configuration (H/L) sensitivity for silicon and three fluids (simple; $\mathrm{v}_{\mathrm{in}}=0.05 \mathrm{~m} / \mathrm{s} ; \varphi=0.95$ )

Figure 4: Optimal configuration change as a result of inlet velocity increase for a Newtonian fluid in silicon

Figure 5: Excess temperature change as a result of inlet velocity and porosity increase for a Newtonian fluid in silicon

Figure 6: The optimal thermal conductance of silicon with increase in velocity and different fluid Power-law exponents for simple micro-channel with a porosity of 0.8

Figure 7: Thermal conductance sensitivity to solid material and porosity variations for a Newtonian fluid

Figure 8: The pressure drop for pseudoplastic versus Newtonian fluid (simple silicon duct)

Figure 9: Three-dimensional complex micro-channel element configuration

Figure 10: Three-dimensional complex micro-channel configuration

Figure 11: Temperature distribution and boundary layer formations (complex)

Figure 12: Optimal geometric configuration sensitivity for three fluids (complex; $\varphi=0.9$ )

Figure 13: Optimal configuration change as a result of inlet velocity increase for a Newtonian fluid (complex)

Figure 14: Excess temperature as a function of inlet velocity and porosity for a Newtonian fluid (complex)

Figure 15: Optimal thermal conductance as a function of inlet velocity (complex; $\varphi=0.85$ )

Figure 16: Thermal conductance sensitivity to porosity and fluid for a complex mixrochannel $(\mathrm{n}=0.5, \mathrm{n}=, \mathrm{n}=1.5)$

Figure 17: Normalised pressure drop over complex micro-channel at a porosity of 0.95

Figure 18: Thermal conductance of a simple micro-channel (silicon) compared to a complex micro-channel for a porosity of 0.9

Figure 19: Normalised pressure drop for a simple micro-channel compared to a complex micro-channel (silicon; $\varphi=0.95$ ) 
Table 1 Two dimensional simpel microchannel mesh refinement study

\begin{tabular}{llll}
\hline Cells & Base size $(\mathbf{m})$ & Thermal Resistance & \% change \\
\hline 21400 & $2.2 \mathrm{E} 0-4$ & 50.7984 & - \\
25586 & $2.0 \mathrm{E}-4$ & 50.6758 & 0.241 \\
30912 & $1.8 \mathrm{E}-4$ & 49.7835 & 1.761 \\
66304 & $1.6 \mathrm{E}-4$ & 49.4732 & 0.623 \\
117400 & $1.4 \mathrm{E}-4$ & 49.3278 & 0.294 \\
\hline
\end{tabular}

Table 2 Three dimensional coplex microchannel mesh refinement study

\begin{tabular}{llll}
\hline Cells & Base size $(\mathbf{m m})$ & $\Delta \boldsymbol{T}_{\boldsymbol{m i n}}$ & \% change \\
\hline 26043 & 1.4 & 6.1930 & - \\
32210 & 1.2 & 6.1360 & 0.921 \\
46424 & 1.0 & 6.2091 & -1.192 \\
77903 & 0.8 & 6.1963 & 0.206 \\
$\mathbf{1 4 6 2 4 5}$ & $\mathbf{0 . 6}$ & $\mathbf{6 . 1 6 8 2}$ & $\mathbf{0 . 4 5 3}$ \\
338342 & 0.4 & 6.1731 & -0.079 \\
\hline
\end{tabular}




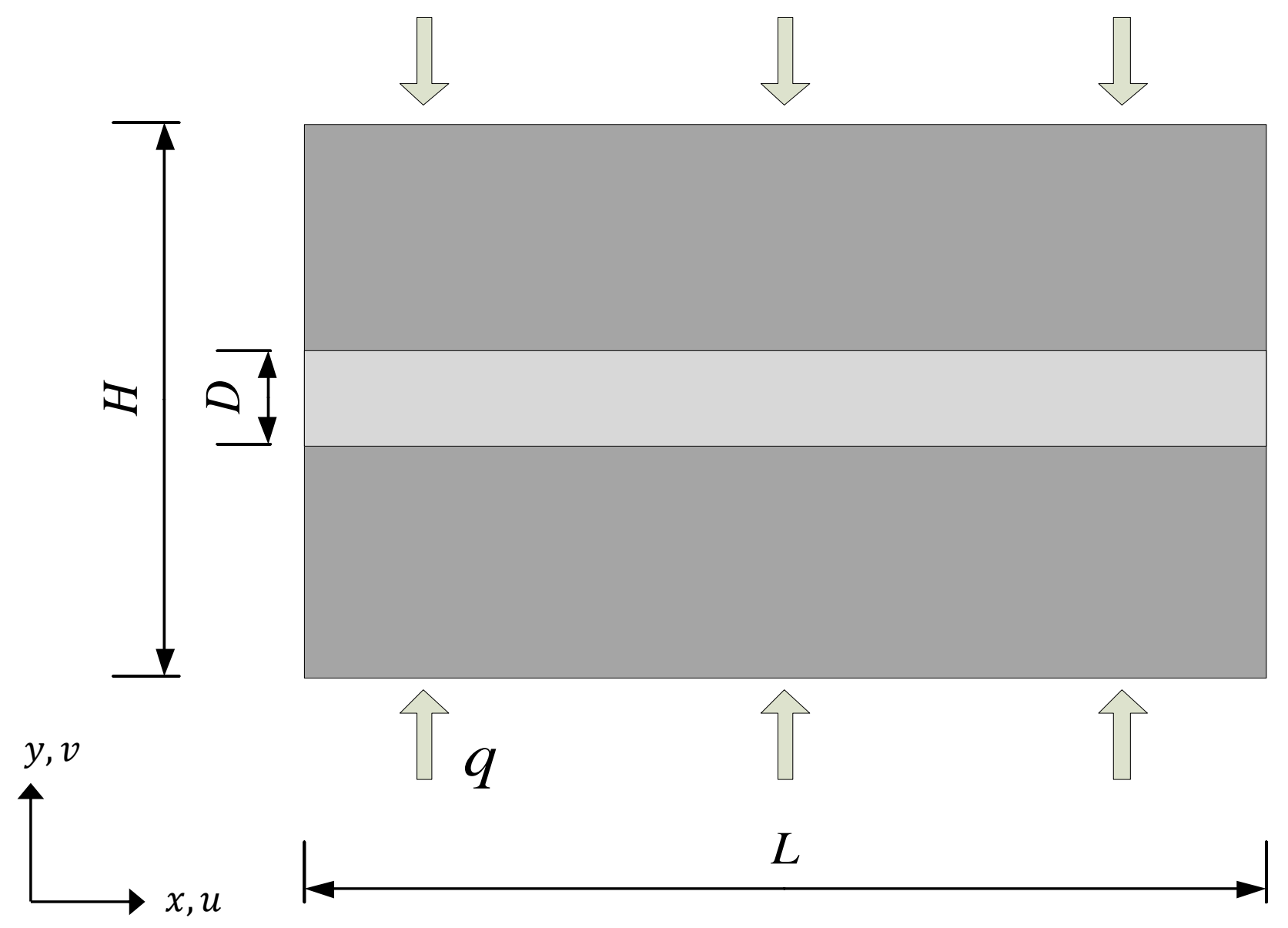

Fig. 1 Two-dimensional simple micro-channel configuration 


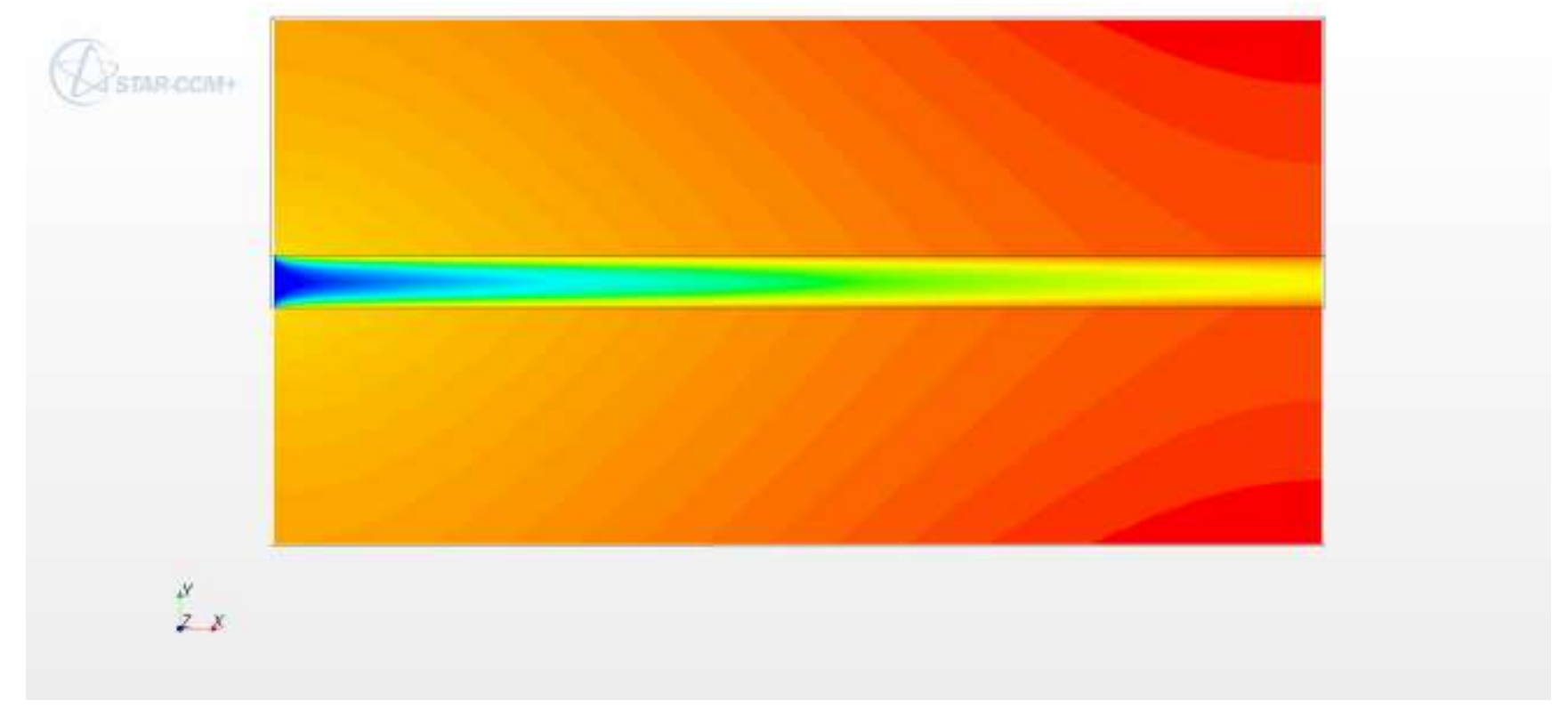

Fig. 2 Temperature distribution and boundary layer formation (simple)

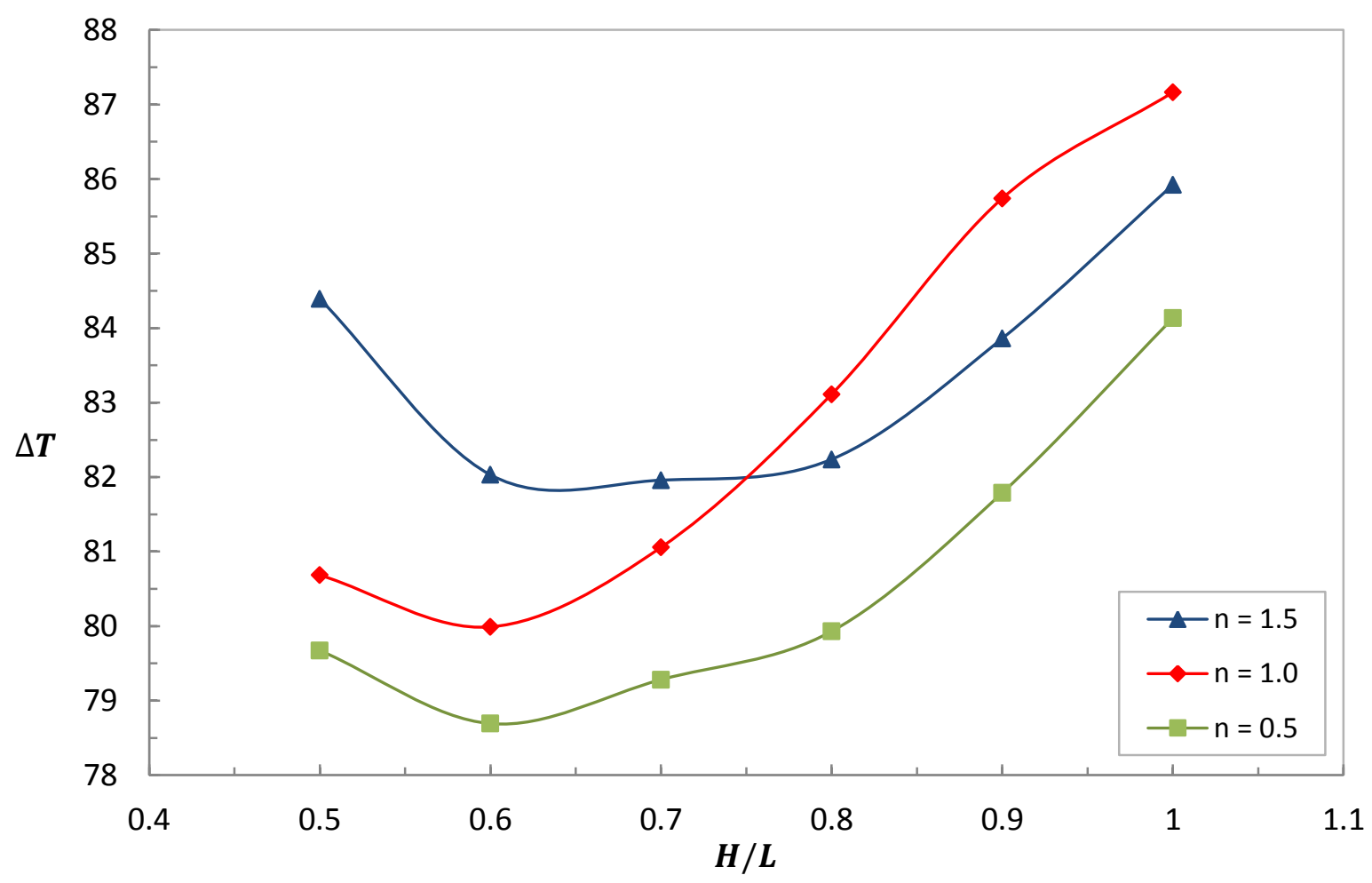

Fig. 3 Optimal geometric configuration $(\boldsymbol{H} / \boldsymbol{L})$ sensitivity for silicon and three fluids (simple; $\mathbf{v}_{\mathbf{i n}}=0.05 \mathbf{m} / \mathbf{s} ; \boldsymbol{\varphi}$ $=0.95$ ) 


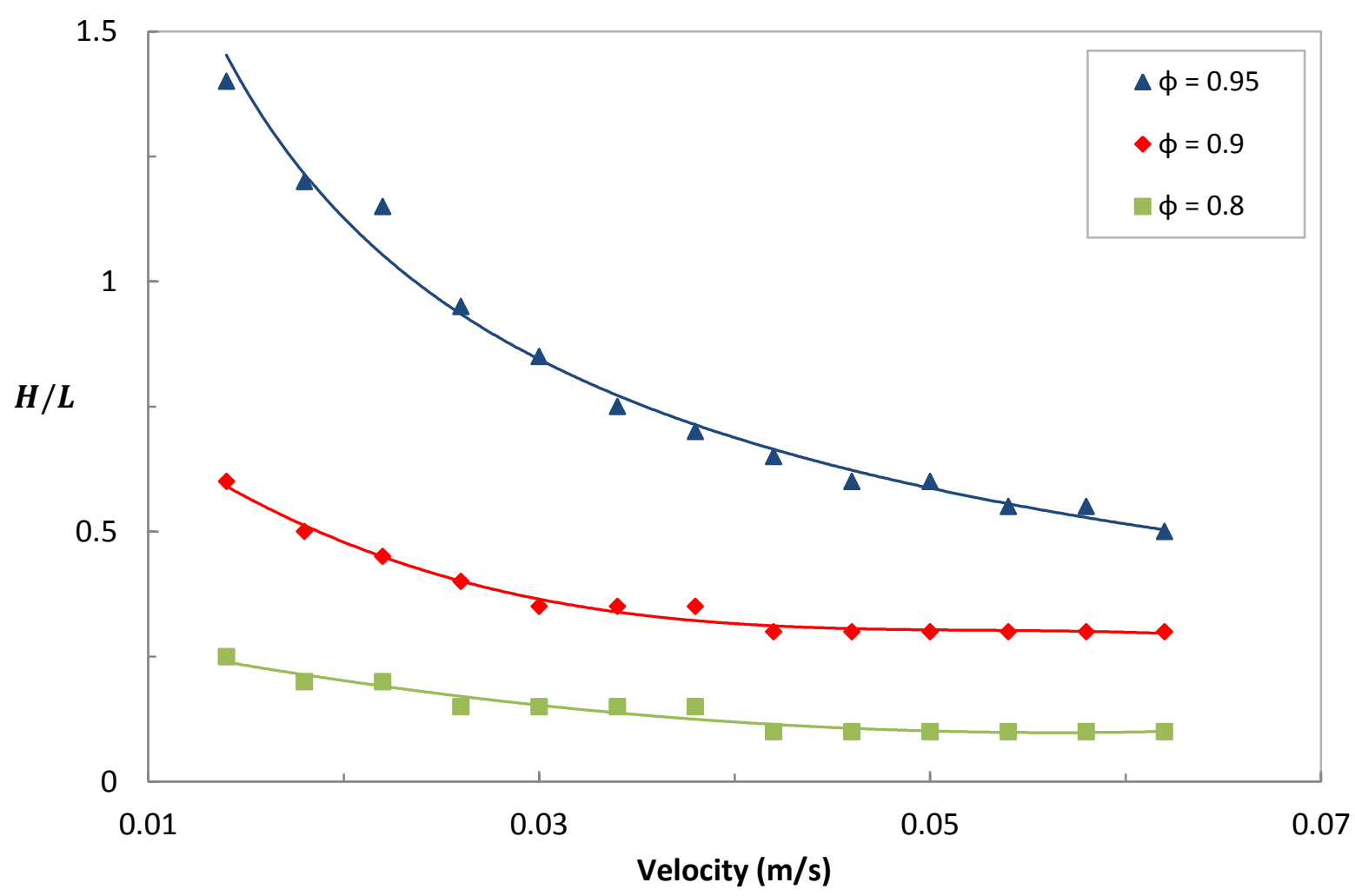

Fig. 4 Optimal configuration change as a result of inlet velocity increase for a Newtonian fluid in silicon

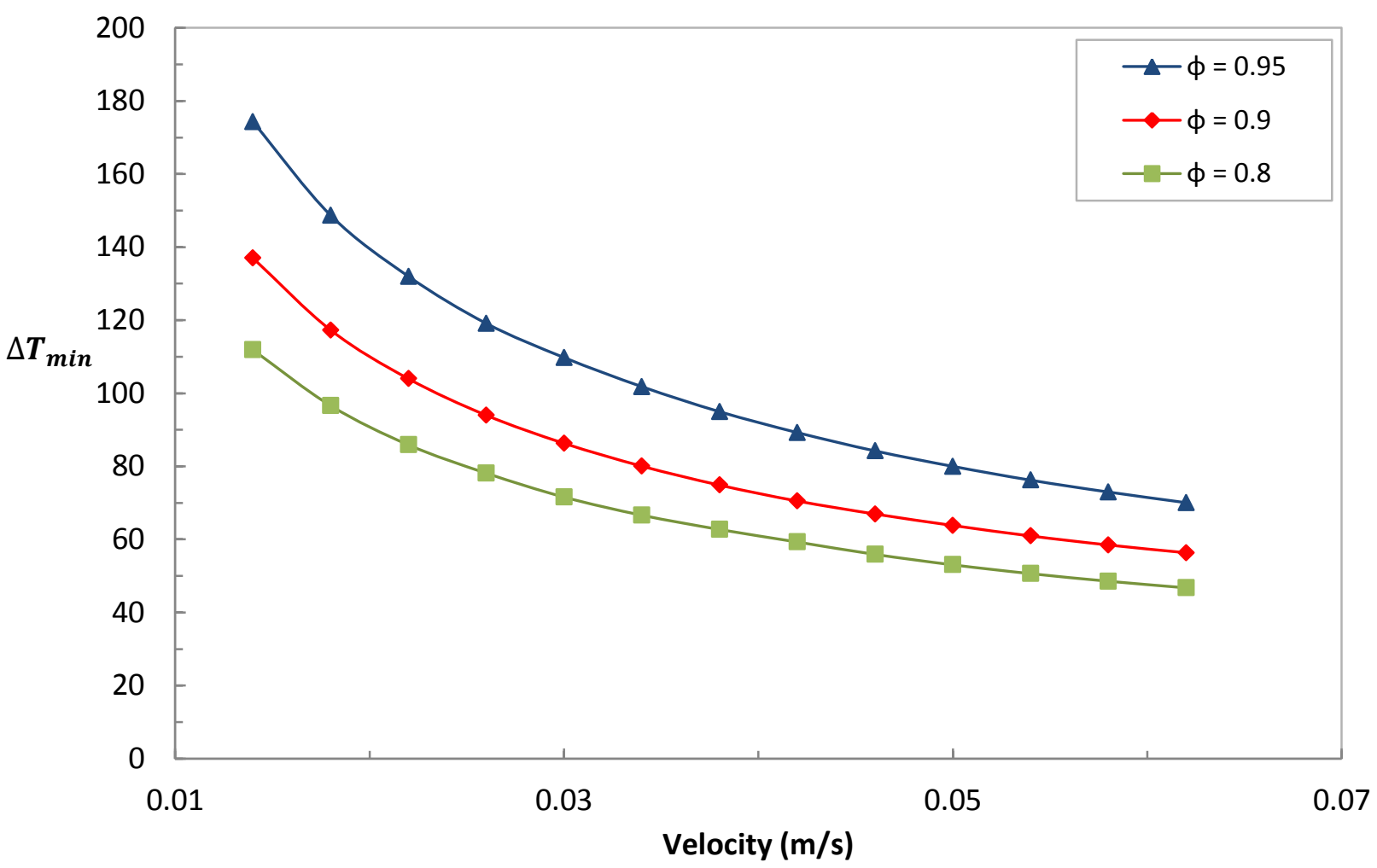

Fig. 5 Excess temperature change as a result of inlet velocity and porosity increase for a Newtonian fluid in silicon 


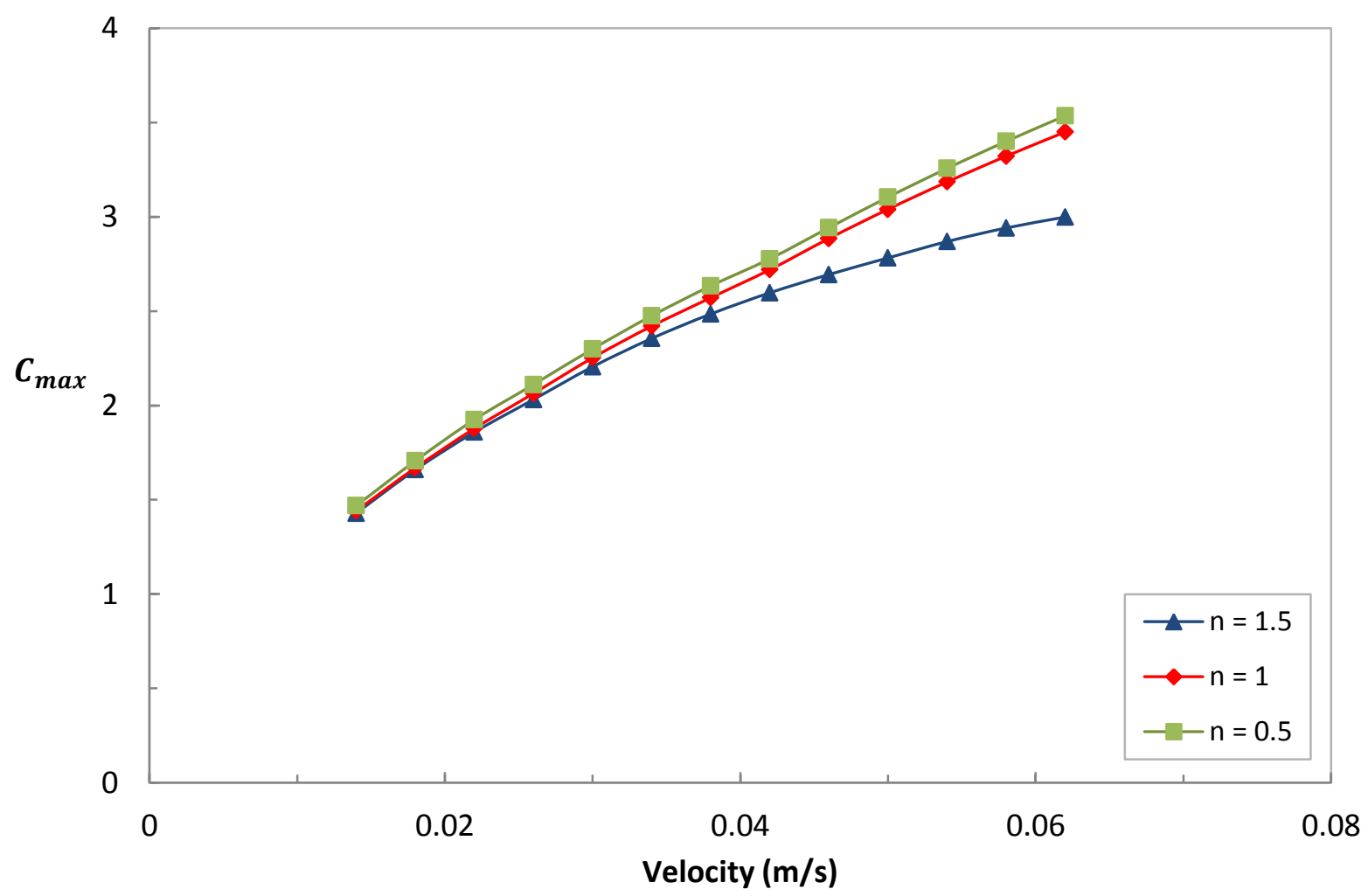

Fig. 6 The optimal thermal conductance of silicon with increase in velocity and different 


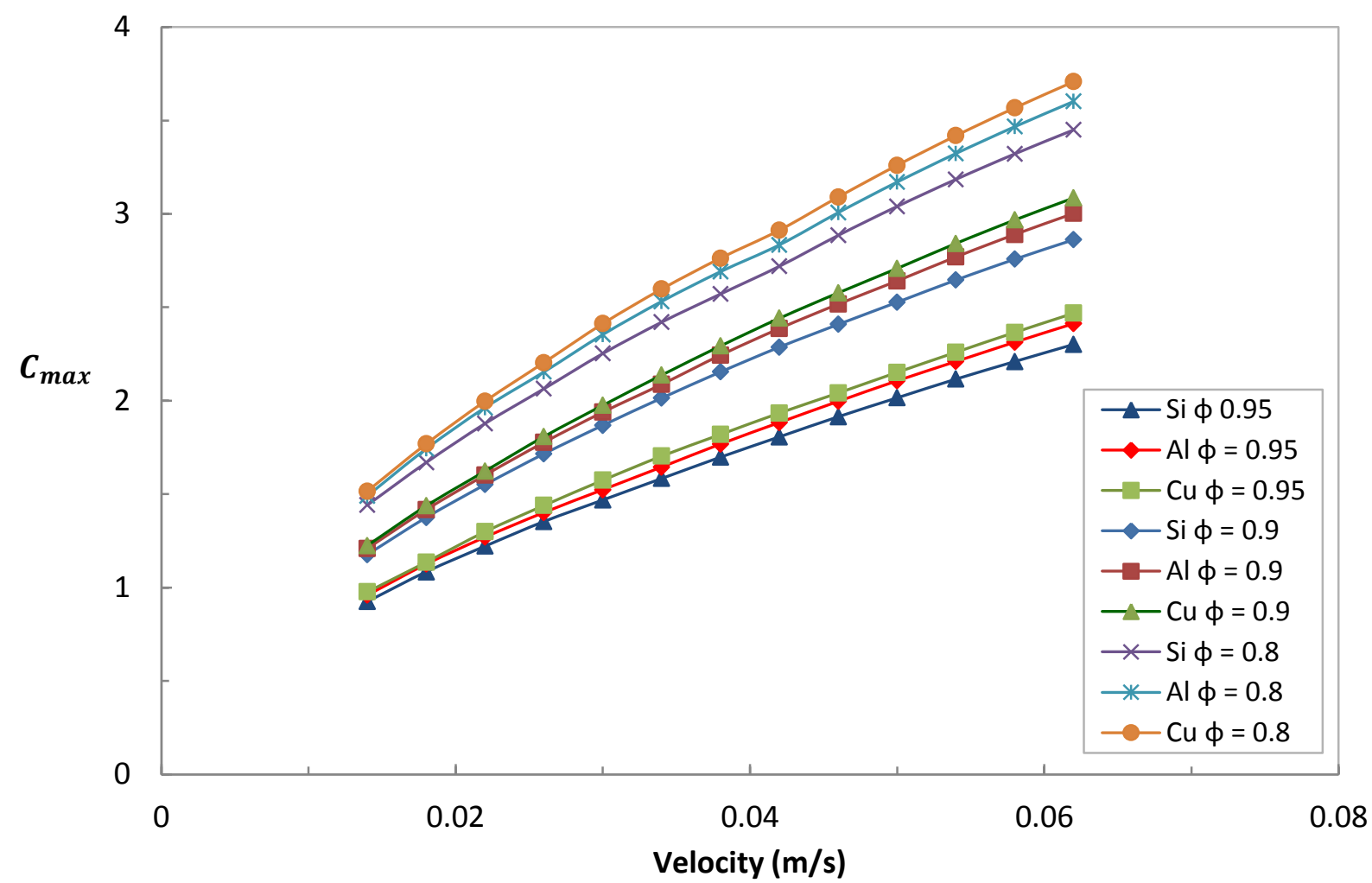

Fig. 7 Thermal conductance sensitivity to solid material and porosity variations for a Newtonian fluid 


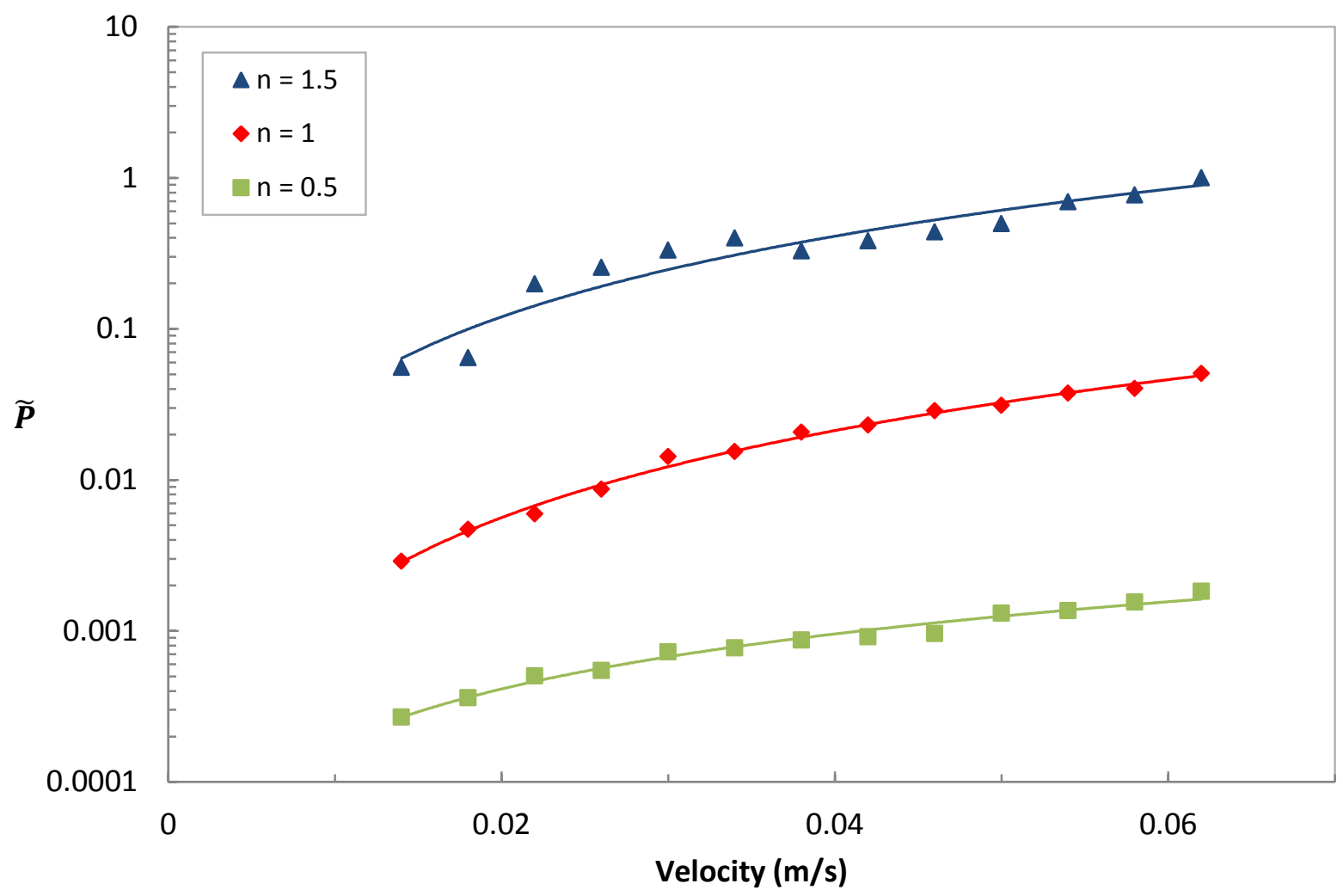

Fig. 8 Normalised pressure drop for pseudoplastic versus Newtonian fluid (simple silicon duct) 


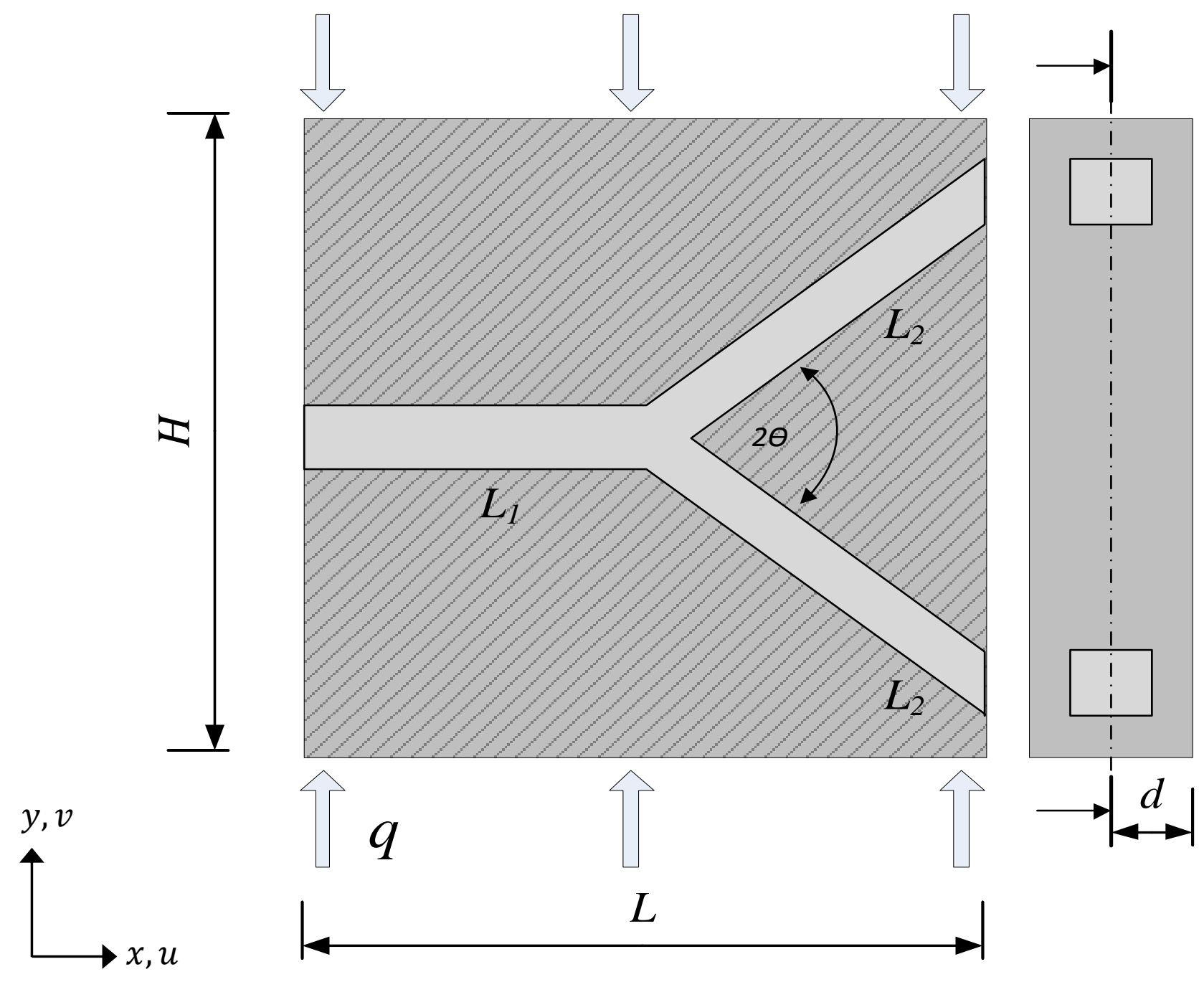

Fig. 9 Three-dimensional complex micro-channel element configuration 


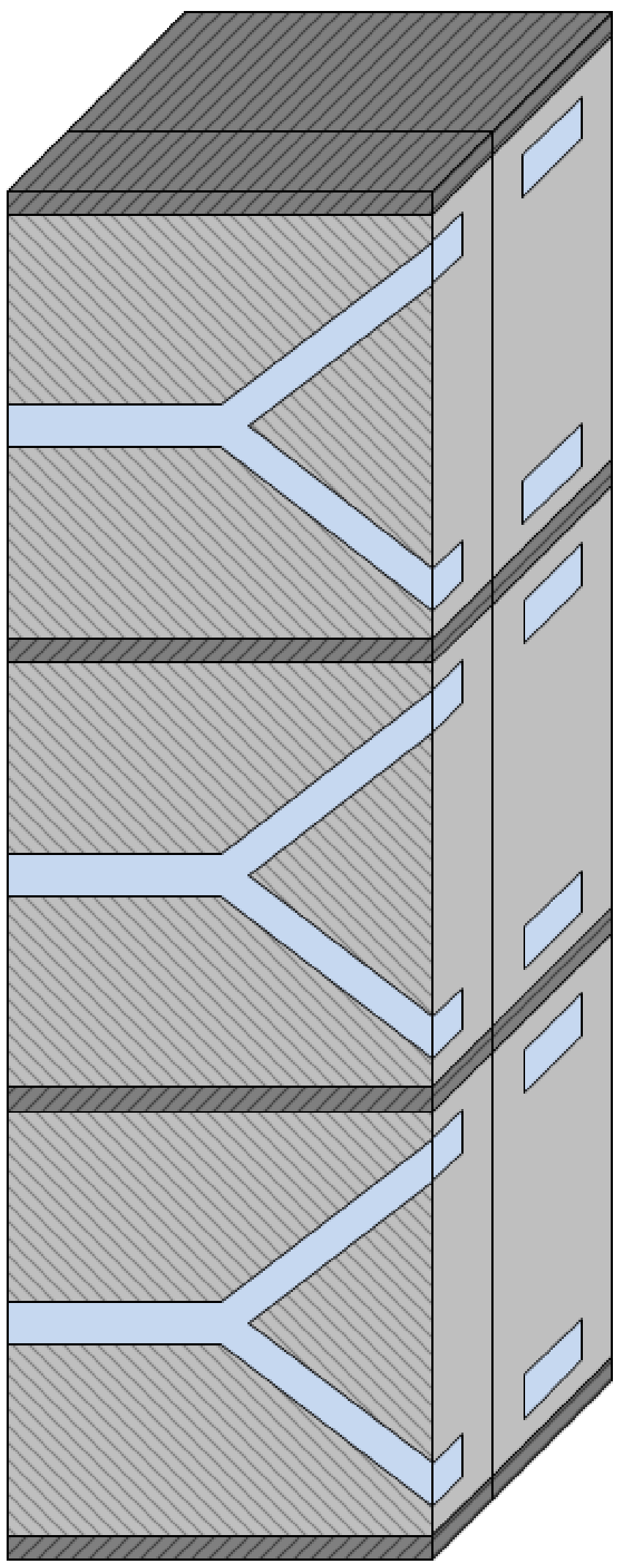

Fig. 10 Three-dimensional complex micro-channel configuration 


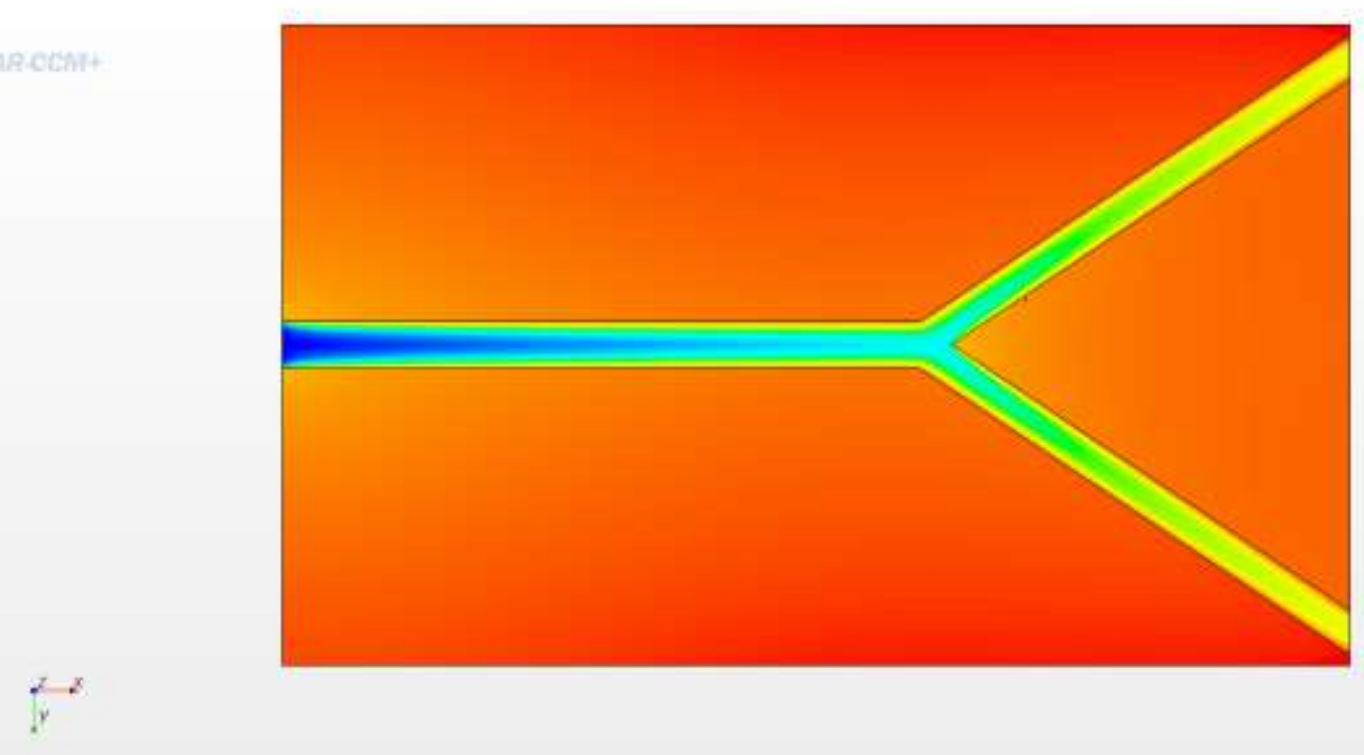

Fig. 11 Temperature distribution and boundary layer formations (complex)

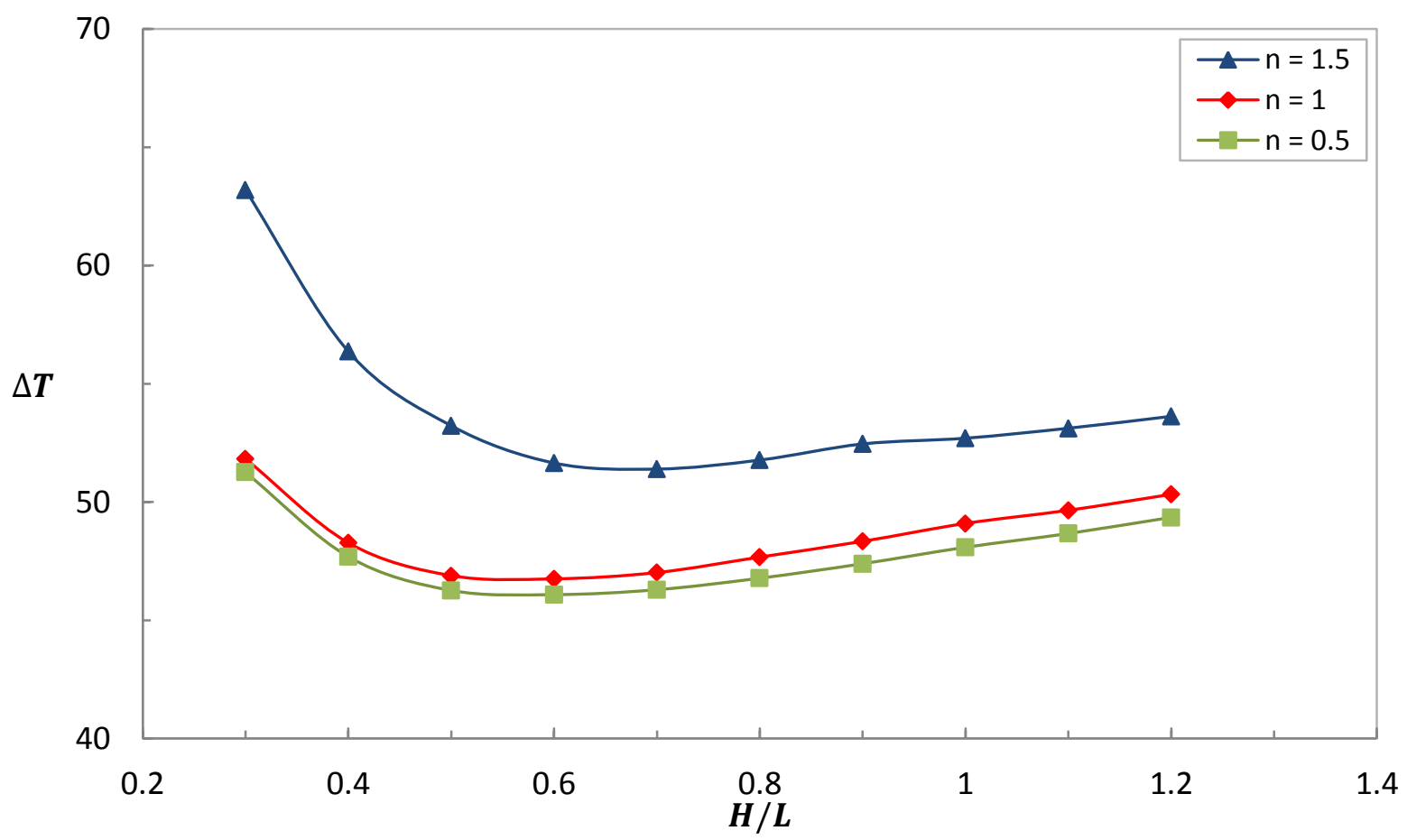

Fig. 12 Optimal geometric configuration sensitivity for three fluids (complex; $\boldsymbol{\varphi}=0.9$ ) 


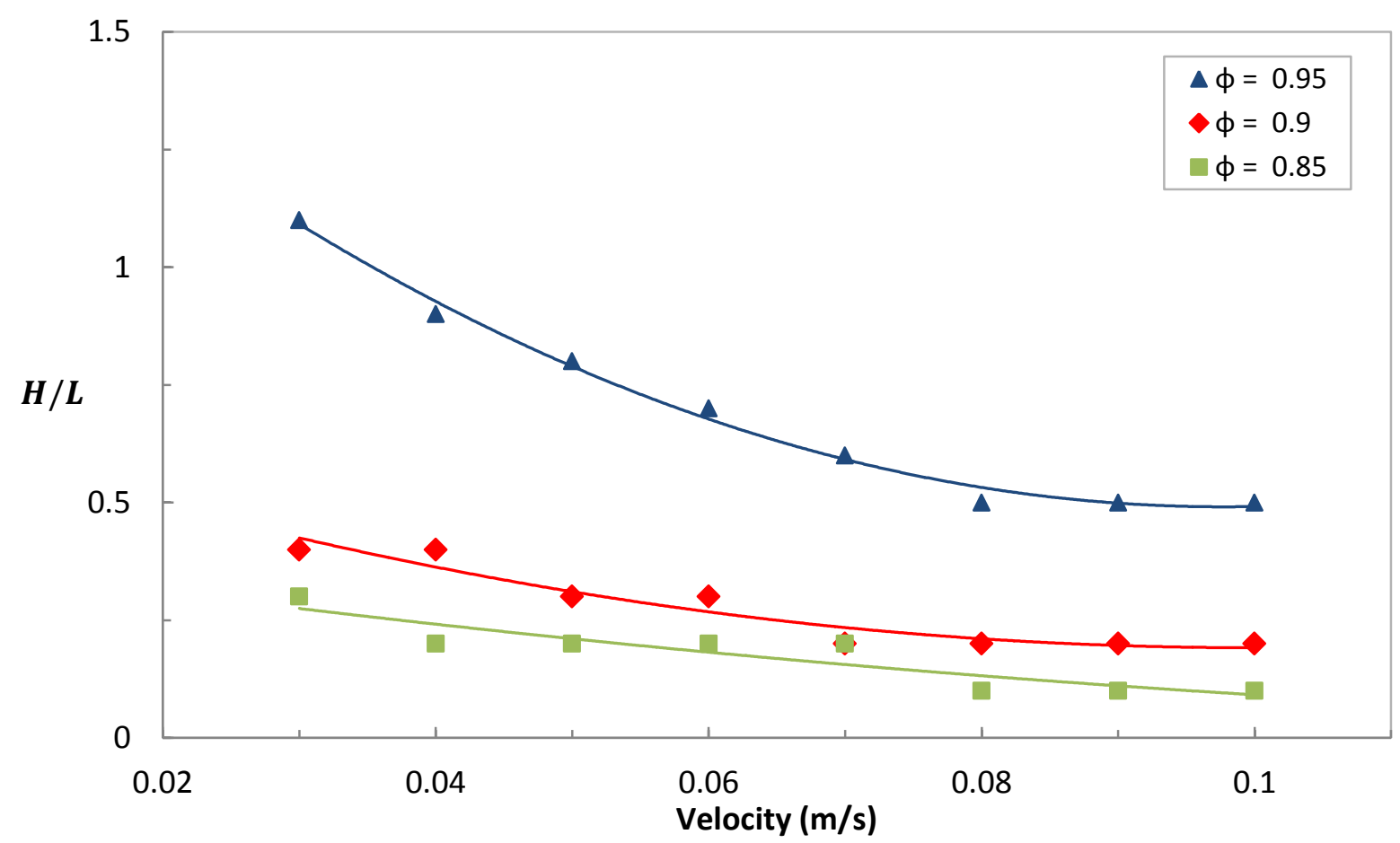

Fig. 13 Optimal configuration change as a result of inlet velocity increase for a Newtonian fluid (complex)

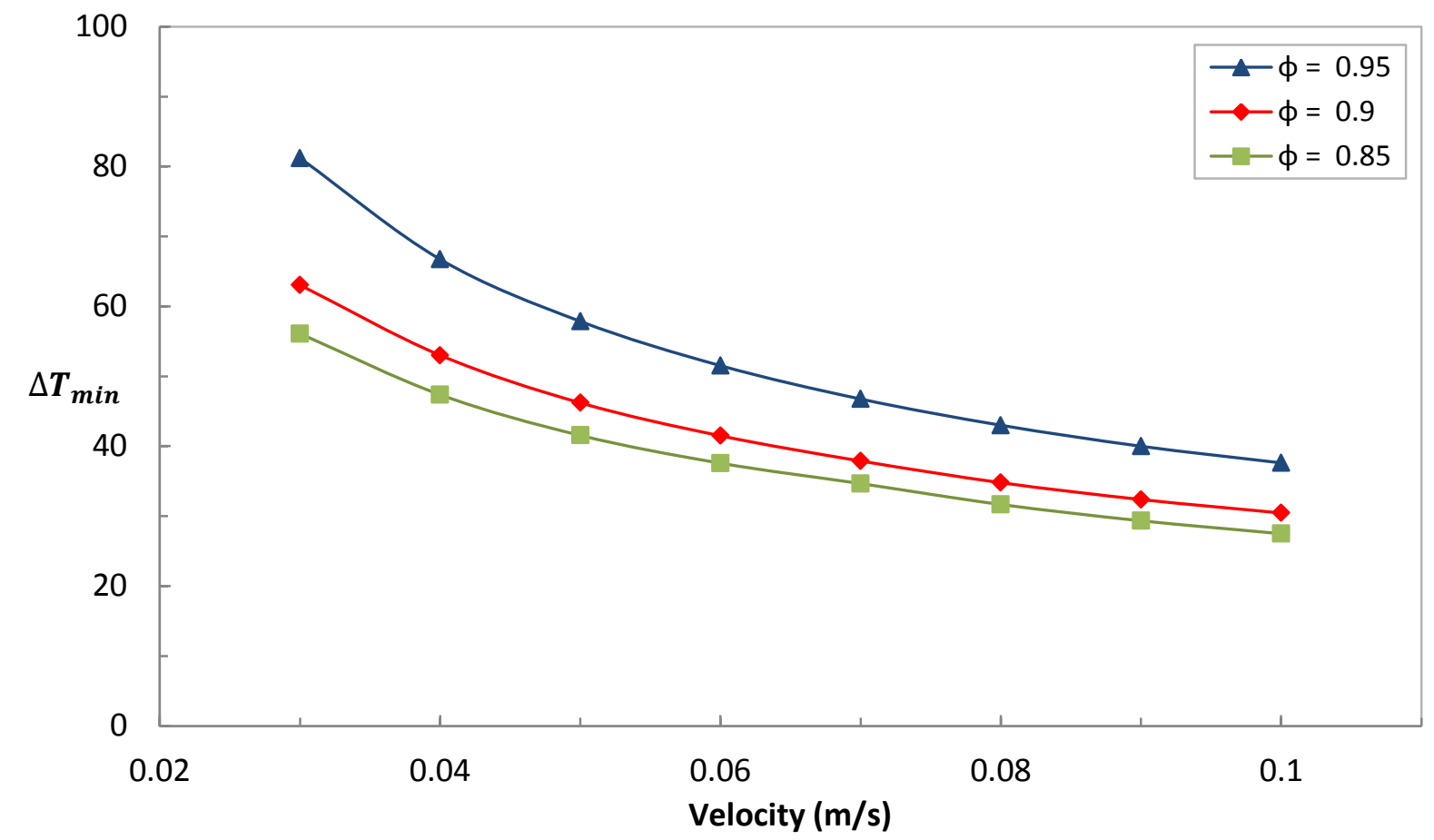

Fig. 14 Excess temperature as a function of inlet velocity and porosity for a Newtonian fluid (complex) 


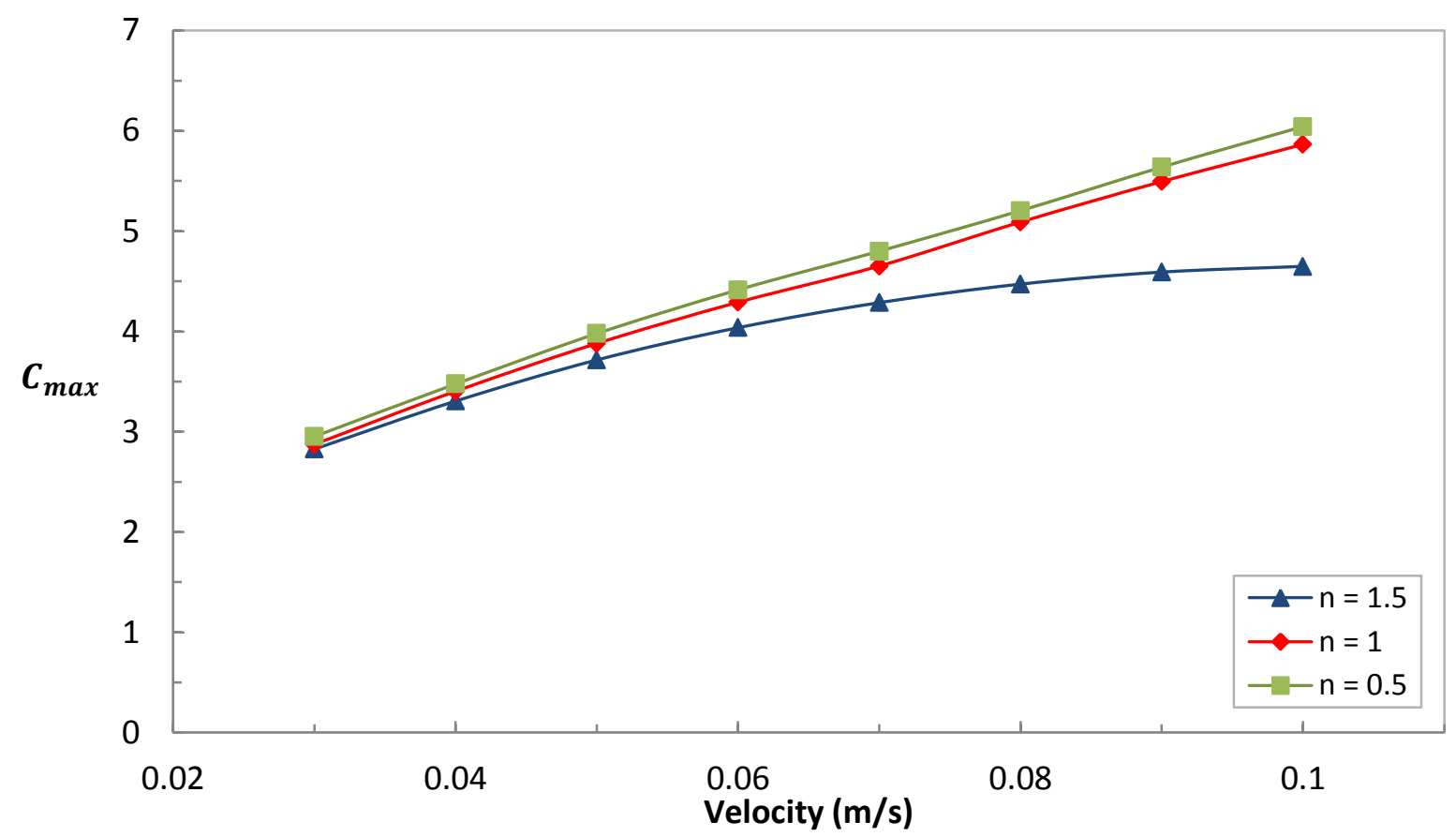

Fig. 15 Optimal thermal conductance as a function of inlet velocity (complex; $\boldsymbol{\varphi}=0.85$ )

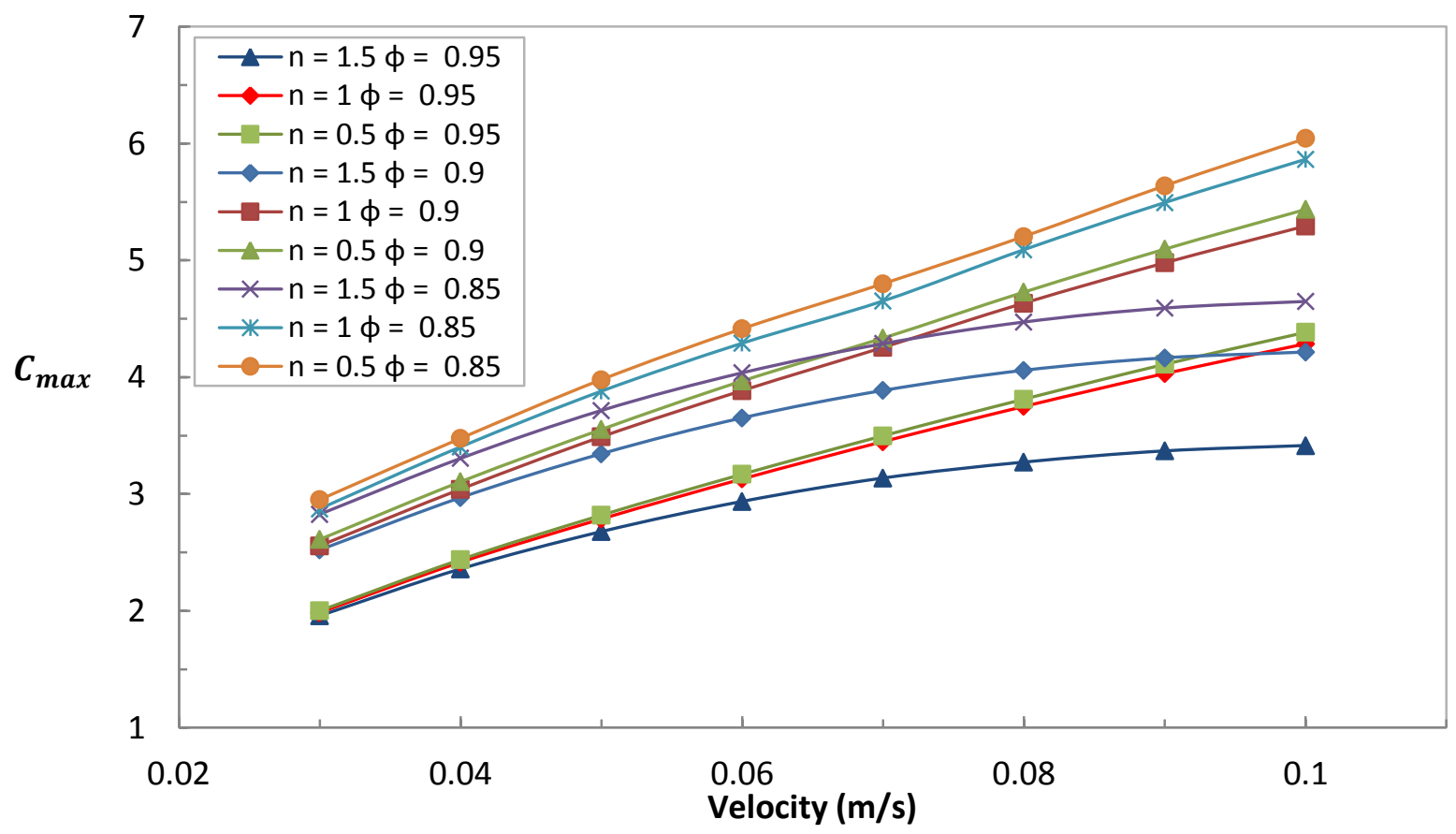

Fig. 16 Thermal conductance sensitivity to porosity and fluid for a complex mixro-channel $(\mathbf{n}=0.5, \mathbf{n}=, \mathbf{n}=$ 1.5) 


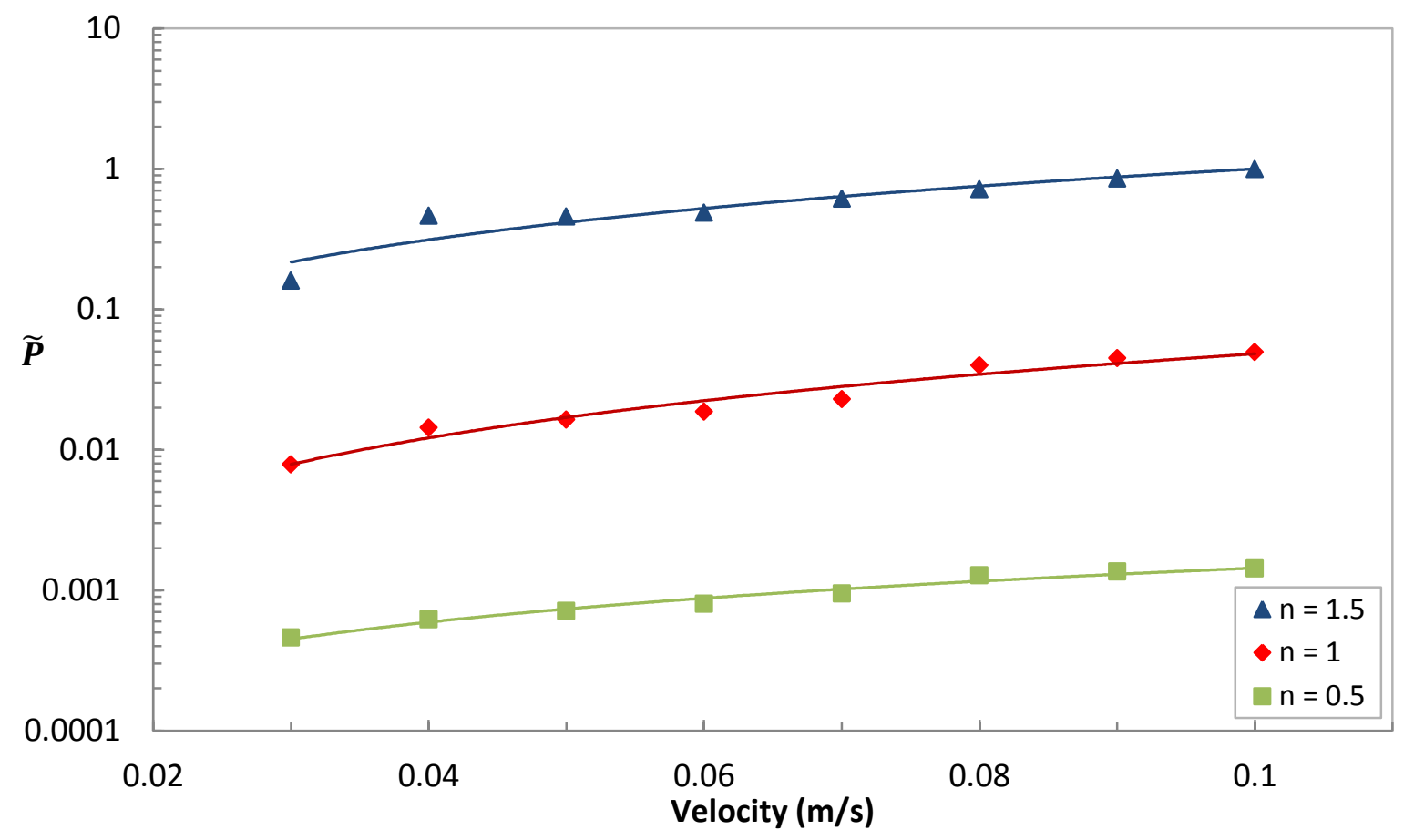

Fig. 17 Normalised pressure drop over complex micro-channel at a porosity of 0.95

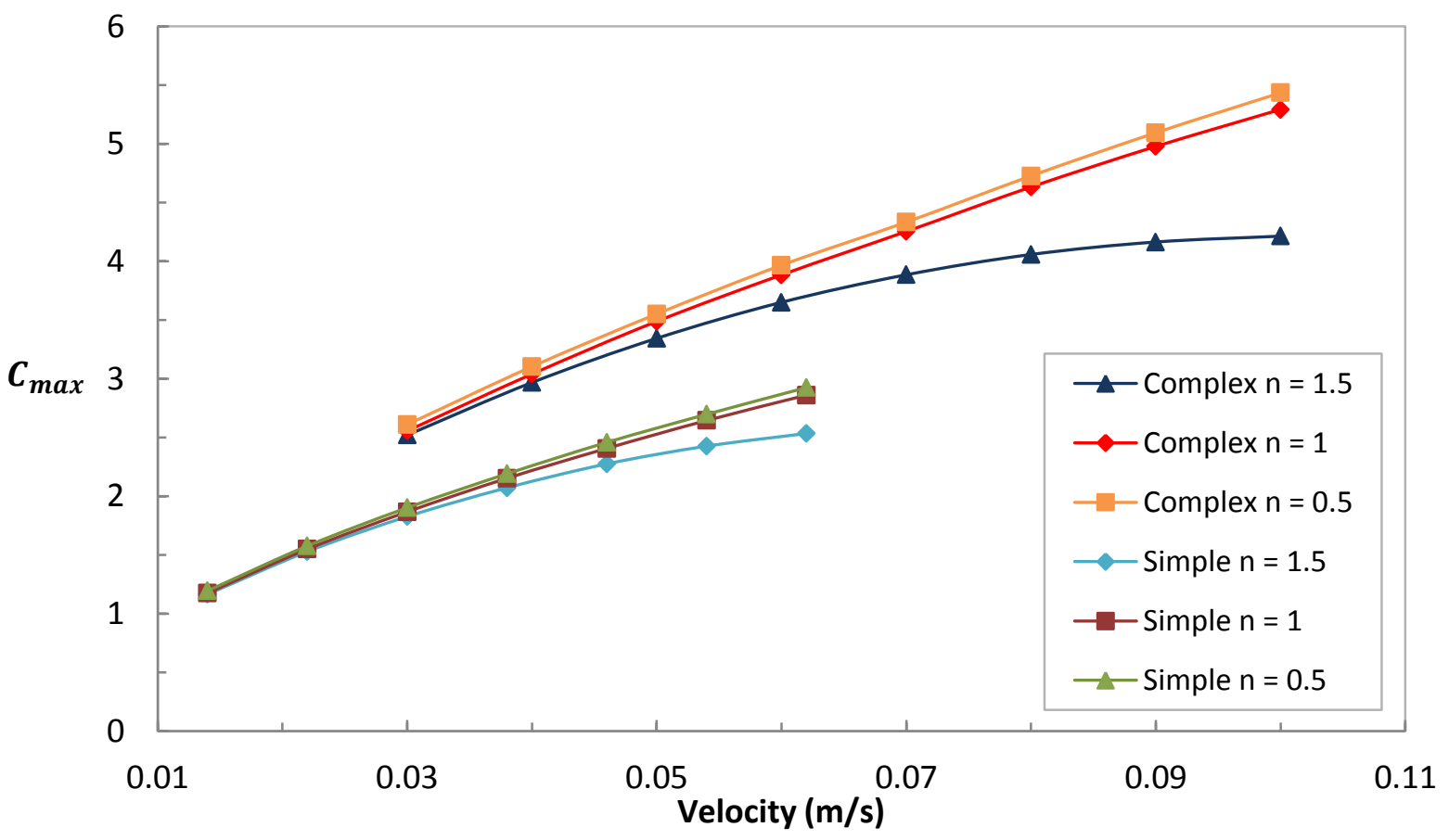

Fig. 18 Thermal conductance of a simple micro-channel (silicon) compared to a complex micro-channel for a porosity of 0.9 


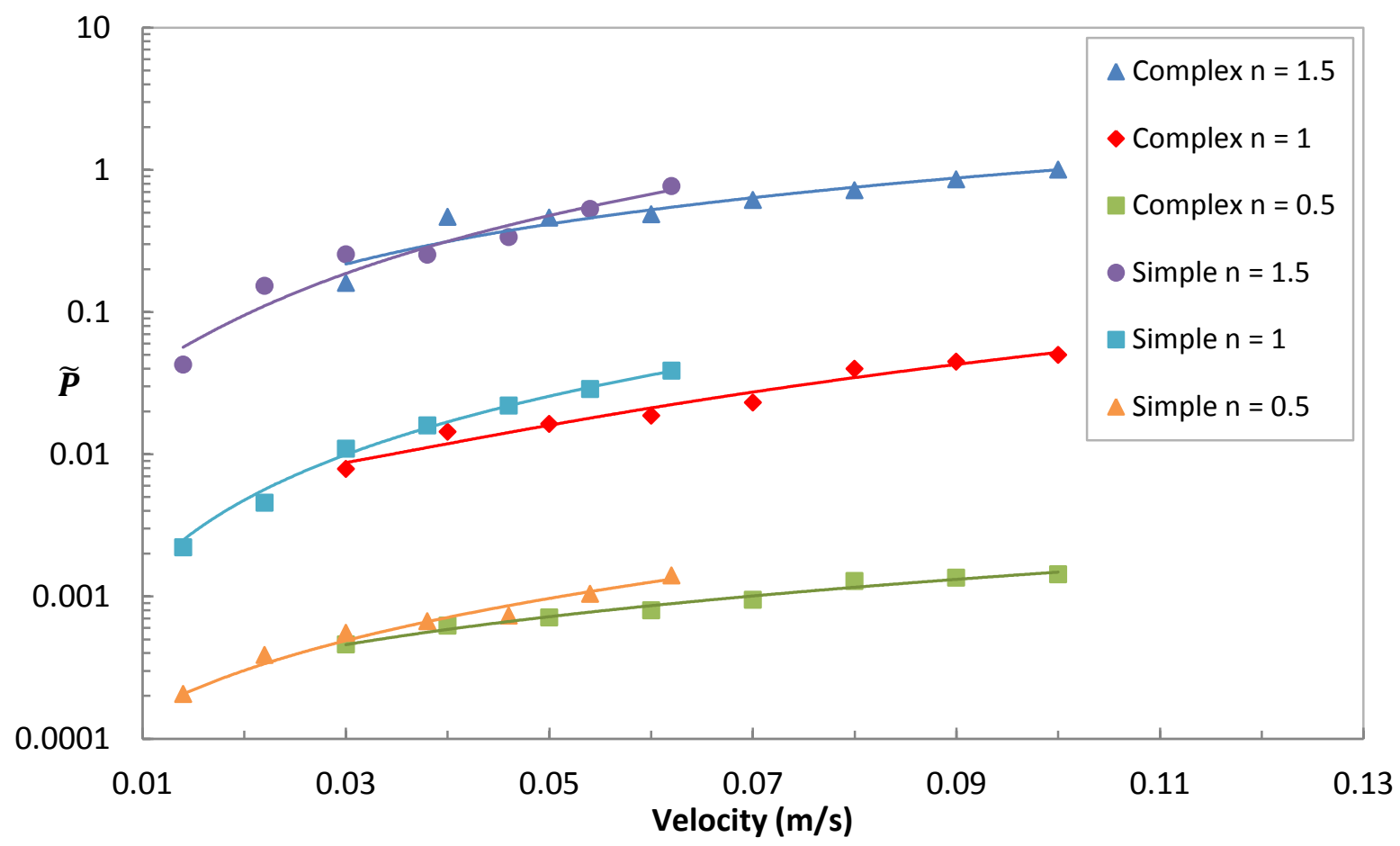

Fig. 19 Normalised pressure drop for a simple micro-channel compared to a complex micro-channel (silicon; $\varphi=0.95)$ 